\title{
Structural-Functional Features of the Thyrotropin Receptor: A Class A G-Protein-Coupled Receptor at Work
}

\author{
Gunnar Kleinau 1,2, Catherine L. Worth ${ }^{3}$, Annika Kreuchwig ${ }^{3}$, Heike Biebermann', \\ Patrick Marcinkowski ${ }^{3}$, Patrick Scheerer ${ }^{2}$ and Gerd Krause ${ }^{3 *}$ \\ ${ }^{1}$ Institute of Experimental Pediatric Endocrinology, Charité-Universitätsmedizin, Berlin, Germany, ${ }^{2}$ Group Protein X-Ray \\ Crystallography and Signal Transduction, Institute of Medical Physics and Biophysics, Charité-Universitätsmedizin, Berlin, \\ Germany, ${ }^{3}$ Leibniz-Institut für Molekulare Pharmakologie (FMP), Berlin, Germany
}

OPEN ACCESS

Edited by:

Rauf Latif,

Icahn School of Medicine at Mount Sinai, USA

Reviewed by: Mihaly Mezei, Icahn School of Medicine at Mount Sinai, USA

Efisio Puxeddu,

University of Perugia, Italy

*Correspondence: Gerd Krause gkrause@fmp-berlin.de

Specialty section: This article was submitted to Thyroid Endocrinology,

a section of the journal Frontiers in Endocrinology

Received: 02 February 2017 Accepted: 03 April 2017

Published: 24 April 2017

Citation:

Kleinau G, Worth CL, Kreuchwig A,

Biebermann H, Marcinkowski $P$,

Scheerer $P$ and Krause G (2017) Structural-Functional Features of the Thyrotropin Receptor:

A Class A G-Protein-Coupled Receptor at Work.

Front. Endocrinol. 8:86. doi: 10.3389/fendo.2017.00086
The thyroid-stimulating hormone receptor (TSHR) is a member of the glycoprotein hormone receptors, a sub-group of class A G-protein-coupled receptors (GPCRs). TSHR and its endogenous ligand thyrotropin (TSH) are of essential importance for growth and function of the thyroid gland and proper function of the TSH/TSHR system is pivotal for production and release of thyroid hormones. This receptor is also important with respect to pathophysiology, such as autoimmune (including ophthalmopathy) or non-autoimmune thyroid dysfunctions and cancer development. Pharmacological interventions directly targeting the TSHR should provide benefits to disease treatment compared to currently available therapies of dysfunctions associated with the TSHR or the thyroid gland. Upon TSHR activation, the molecular events conveying conformational changes from the extra- to the intracellular side of the cell across the membrane comprise reception, conversion, and amplification of the signal. These steps are highly dependent on structural features of this receptor and its intermolecular interaction partners, e.g., TSH, antibodies, small molecules, G-proteins, or arrestin. For better understanding of signal transduction, pathogenic mechanisms such as autoantibody action and mutational modifications or for developing new pharmacological strategies, it is essential to combine available structural data with functional information to generate homology models of the entire receptor. Although so far these insights are fragmental, in the past few decades essential contributions have been made to investigate in-depth the involved determinants, such as by structure determination via X-ray crystallography. This review summarizes available knowledge (as of December 2016) concerning the TSHR protein structure, associated functional aspects, and based on these insights we suggest several receptor complex models. Moreover, distinct TSHR properties will be highlighted in comparison to other class A GPCRs to understand the molecular activation mechanisms of this receptor comprehensively. Finally, limitations of current knowledge and lack of information are discussed highlighting the need for intensified efforts toward TSHR structure elucidation.

Keywords: thyroid-stimulating hormone receptor structure, signal transduction, homology models, glycoprotein hormone receptors, arrestin interaction, G-protein interaction, structure-function relationships, oligomers

Abbreviations: GPHR, glycoprotein hormone receptor; LHCGR, lutropin/choriogonadotropin receptor; FSHR, folliclestimulating hormone receptor; TSHR, thyroid-stimulating hormone receptor; TSH, thyroid-stimulating hormone; GPCR, G-protein-coupled receptor; TMH, transmembrane helix; ECL1/2/3, extracellular loops 1/2/3; ICLs 1/2/3, intracellular loops $1 / 2 / 3$; SD, serpentine domain; CAM, constitutively activating mutation; WT, wild type; ECD, ectodomain; IP, inositol phosphate. 


\section{INTRODUCTION}

The thyroid-stimulating hormone (TSH) or thyrotropin (1) receptor (TSHR) (2-6) is a member of the class A G-proteincoupled receptors (GPCRs) (7). Evolutionary close relatives are the two receptors for the gonadotrophic hormones: follitropin (FSH) (8) and lutropin (LH)/choriogonadotropin (CG) (9). The follicle-stimulating hormone receptor (FSHR) and the LHCGR together with the TSHR constitute the sub-family of glycoprotein hormone receptors (GPHRs) (10). The TSHR is essential for thyroid growth and function (11-13) and activates different G-protein subtypes (14-17) and signaling pathways (18-20), whereby Gs- and Gq-induced signaling are probably of highest importance $(13,21-24)$. TSH and its receptor are required for thyroid hormone synthesis and release in the thyroid gland (25). Dysfunctions of the TSHR are the underlying cause of various gain- or loss-of-function phenotypes associated with thyroid malfunction [reviewed in Ref. (26)]. It has been suggested that the TSHR is involved in the development and mechanisms of ophthalmopathy $(16,27-31)$.

For decades, the TSHR and associated molecular mechanisms, such as ligand binding $(32,33)$, cell-surface expression, or induced signaling cascades, were studied with the purpose to not only understand the different steps in signal transduction, their regulation, and specificity but also to receive insights into the related physiological aspects $(13,20,34-38)$ or to develop tools for pharmacological treatment $(39,40)$. Consequently, a huge amount of specific data and information from genetic approaches (site-directed modifications), pathogenic conditions, protein structure studies, biochemical and biophysical analyses are available [see also the information resource of Sequence Structure Function Analysis for GPHR at http://www.ssfa-gphr.de (41-44) which contains $>1,500$ pathogenic and site-directed mutations; comparison of functional data enabled due to normalization as percentage of wild type (WT)].

This raises the following questions, what do we currently know about the complex scenario of signal transduction by the TSHR and what is currently far from our understanding? To answer these questions, here we summarize and discuss the current knowledge about the TSHR with a specific emphasis on structural aspects of receptor activation. This comprises the TSHR structure itself, complexes between this receptor and interacting proteins, and also the transition between different conformations related to different functional processes. For these purposes, the available-albeit fragmental-structural information for the TSHR and its interacting proteins will first be described followed by an assembling of this knowledge into homology models of the entire receptor highlighting the structural and functional specificities in relation to the signal transduction processes.

For understanding of "signal transduction" and related details described in the following sections, it is essential to keep in mind that the 3-dimensional TSHR structure is constituted by interplaying domains (Figure 1) located in different cellular environments. This fact is due to the principal molecular function of GPCRs as hubs to transduce signals. The "signal" is induced by ligand binding at the extracellular site and transmitted via structural rearrangements in the transmembrane-spanning receptor

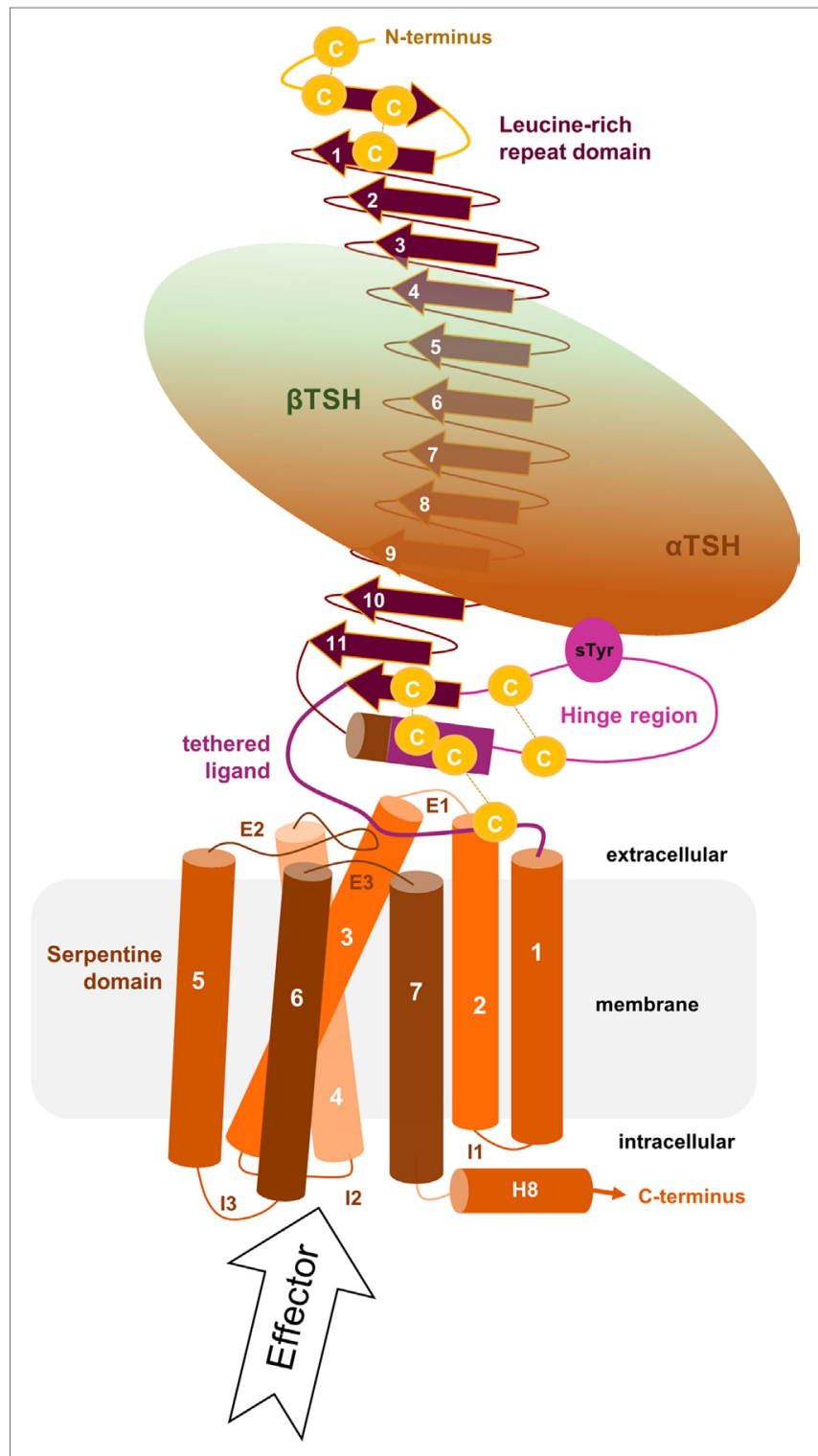

FIGURE 1 | Scheme of the putative overall thyroid-stimulating hormone receptor (TSHR) protein structure. This scheme shows the overall structure and domain assembly of the TSHR. Significant features are highlighted, e.g., the sulfated tyrosine in the hinge region that is involved in hormone binding. The leucine-rich repeat domain (LRRD) together with the hinge region constituting the extracellular receptor part. The seven transmembrane helices and their connecting loops arrange the serpentine domain, which spans the membrane from the extra- to the intracellular side. A tethered ligand located between the extracellular loops has been proven and is composed of amino acids from both C-terminal ends of the LRRD and the hinge region.

region [serpentine domain (SD) comprised transmembrane helices including their connecting loops] toward intracellular effectors. A receptor like the TSHR therefore not only receives a signal but it is also a trigger, catalyzer, and regulator for specific physical or biophysical information. Moreover, the communication inside the protein is regulated by several specific amino acids or groups of amino acids at diverse structural parts that are responsible, for instance, for intermolecular contacts (e.g., for 
ligand binding) or intramolecular interactions (e.g., for maintenance of a specific conformation). In consequence, each part of the receptor has individual functional priorities that are interrelated with highly adapted structural features. The entire process of signal transduction is a sequence of concerted events that are disturbed under pathogenic conditions and must be circumvented by pharmacological interventions (45-52).

\section{AVAILABLE STRUCTURAL INFORMATION}

\section{The Extracellular Leucine-Rich Repeat Domain (LRRD) and the Hinge Region}

The extracellular LRRD and hinge region of the TSHR constitute the N-terminal extracellular receptor part (Figure 1), which is remarkably large (around 400 amino acids) compared to other class A GPCRs $(10,53)$. TSH and antibodies (activating, neutral, and blocking antibodies) interact with the receptor in this region [e.g., Ref. (54-58)]. The LRRD and the hinge region contain six asparagine-linked glycosylation sites (N-Xaa-S/T) that were already investigated intensively (59-62), and it was suggested that glycosylation of at least four sites appears necessary for expression of the functional TSHR (59).

The LRRD comprises repeats of specific amino acid sequences between 20 and 30 residues in length [for a detailed description of GPHR LRRD repeats, see Ref. (63)] known from available TSHR and FSHR crystal structures (56, 57, 64, 65) (Figure 2). The LRRD has a scythe blade-like shape with a slight twist from the $\mathrm{N}$ - toward the C-terminus. Hydrophobic amino acid side chains stabilize the inner core of the LRRD and aromatic interactions specifically are of high importance to maintain the backbone of the assembled repeats (Figure 3). Although the so far solved TSHR LRRD crystal structures showed a maximum of nine repeats $(56,57)$, based on homology modeling combined with mutagenesis studies (53), it was suggested that this domain is actually composed of 11 repeats (r1-r11 in Figure 3) - which was confirmed afterward by the recently solved FSHR LRRD structure (65). Interestingly, in contrast to other LRRDs with a similar fold (66-68), only the last C-terminal repeat of the GPHR LRRD is characterized by a short helix motif. Located in this helix are two cysteines at positions 283 and 284 that are known to interact with two cysteines at the C-terminal hinge region $(65,69)$. These disulfide bridges are important for adjusting both extracellular parts to each other and simultaneously anchoring the entire extracellular region close to the SD (Figure 3B). Moreover, gainof-function mutations at position serine 281 leading to constitutive receptor activation were identified in patients $(70,71)$. This amino acid is also located in the helical part of the LRRD C-terminus and is crucial for activation $(69,70,72,73)$.

In the GPHR subfamily, the hinge region structurally links the LRRD with the SD (77). Unfortunately, little is known about the entire structure of the TSHR hinge region for several reasons. First of all, the TSHR hinge region is most likely not a self-folding domain (53). It might be that only parts of this region are specifically folded, or that interacting receptor fragments and/or the bound ligand are necessary to stabilize the hinge region in a specific conformation.
Related to this is the fact that the TSHR can be enzymatically cleaved at two sites in the hinge region $(78,79)$, which is also a prerequisite for shedding $(78,80-84)$ of the disulfide bridges located between the LRRD and the hinge region or inside the hinge region (Figures $\mathbf{1}$ and $3 \mathbf{B}$ ). Shedding and cleavage in combination finally releases the so-called "receptor-subunit $A$ " (constituted by the LRRD and parts of the hinge region) from the "receptor-subunit B" (C-terminal part of the N-terminus together with the SD) and cleavage plus shedding are unique to the TSHR in the group of GPHRs. This separation is likely related to the pathogenic occurrence of autoimmune antibodies against the TSHR $(20,34,79,85,86)$. The cleaved peptide is termed "C-peptide" (approximately 50 amino acids in length), and it is still under debate how this process is related to physiological functions, signaling regulation, or pathogenic conditions $(79,84,87-89)$. In any case, it is completely unknown how the C-peptide is folded or contributes to inter- and intramolecular interactions. This question remains important for understanding differences among the GPHRs.

From the crystal structure complex of FSHR ectodomain (ECD)/FSH only fragments of the hinge region are known, with a portion in the middle of the hinge region being unresolved (65). This missing part corresponds to TSHR residues 305-380. The entire TSHR hinge region is predicted to span positions 289-409 (53). However, the solved FSHR ECD crystal structure and derived models for the ECD TSHR $(90,91)$ highlight that the $\mathrm{N}$ - and $\mathrm{C}$-terminus of the hinge region are essential for receptor functions like TSH binding and signal transduction. In detail, a third extracellular disulfide bridge between Cys301 and Cys390 [which is not conserved in GPHRs in general, reviewed in Ref. (9)] constrains the close interplay between the $\mathrm{N}$ - and C-terminus of the hinge region (Figure 3B). Cysteine 398 is located in a small beta-strand that is arranged parallel to the last beta-strand of the LRRD. This feature stabilizes the LRRD/ hinge region complex, which may explain together with the two essential disulfide bridges Cys283/Cys398 and Cys284/Cys408 why this part was also solved in the FSHR crystal structure (65).

Moreover, the FSHR ECD crystal structure bound with FSH provided for the first time details of the second hormone-binding site of GPHRs around a conserved sulfated tyrosine (sTyr) (functionally corresponds to sTyr385 in TSHR). This tyrosine binds into a pocket between the hormone subunits and strongly contributes to hormone-binding properties (76), although small differences among the GPHRs were observed $(92,93)$. Generally, the hinge region of GPHRs is the least conserved receptor part $(10,63)$ and is therefore responsible for several differences concerning associated functions like hormone binding or induction of signaling pathways $(94,95)$.

\section{The Membrane-Spanning SD}

Currently, no structural information for the SD, comprising the seven membrane-spanning helices and respective connecting loops, has been experimentally determined yet for the TSHR or other GPHRs (Figure 2). This precludes detailed insights being made about amino acid interactions (at the atom level) and also the arrangement of the domains (SD, LRRD, and hinge region) or complexes to each other. However, it can be assumed that 


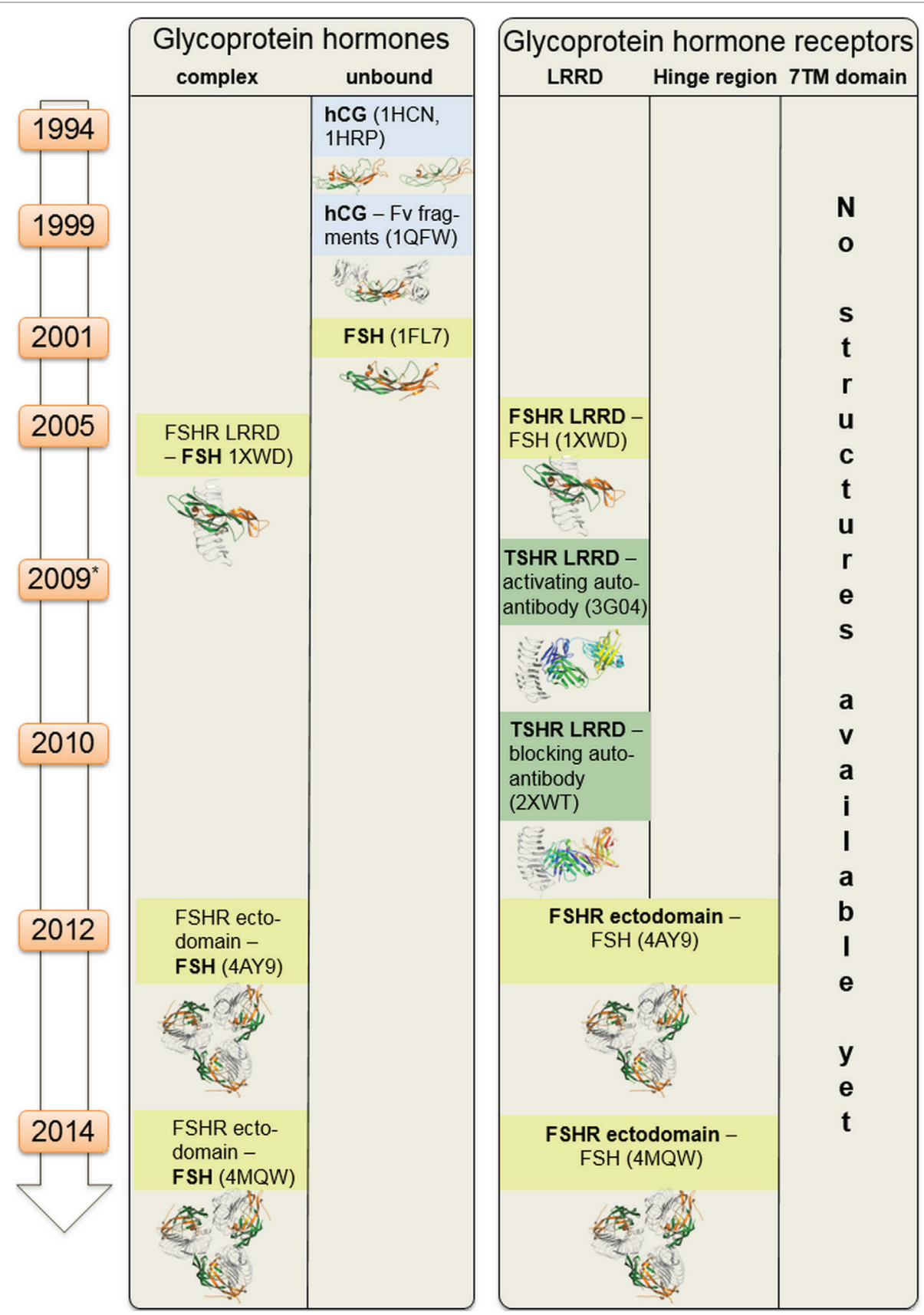

FIGURE 2 | Available structural information for glycoprotein hormone receptors (GPHRs) and GPHs. This scheme summarizes structural information that is available for the GPHRs and GPHs. Since 1994 starting with the first crystal structure of human choriogonadotropin, few further endogenous ligand structures (such as from follitropin or thyroid-stimulating hormone receptor autoantibodies -in complexes or unbound) were solved. Based on the high amino acid sequence similarity, each of these structures can also serve as structural templates for models of receptors and hormones where no structural information is available so far. Moreover, these structural data can be assembled into larger complexes (see Figures 6-8).

the TSHR has the same general assembly of the transmembrane helices as observed for all class A GPCRs because they share a common structural organization (96-99). Thus, experimentally determined structures of other GPCRs can be used as a proxy to generate TSHR models by using homology modeling techniques (100-103). This has been done several times in the past for different purposes [e.g., Ref. $(45,90,104-107)]$. These models were helpful for elucidating mechanisms of pathogenic mutations $(26,108,109)$, allosteric small-molecule binding $(45,48,49,110)$, or G-protein and arrestin coupling (111) and guided more rational experimental approaches by suggesting potential interactions or mechanisms, in advance of already available knowledge. These experiments, in turn, were useful for refining or proving model-based predictions. 
How can a TSHR model based on already solved crystal structures of other GPCRs be generated? Initial attempts at building TSHR models used those GPCR crystal structure templates available at the time: (1) inactive conformations-rhodopsin [PDB entry 1F88 (112)], beta-2-adrenergic receptor [ADRB2, PDB entry 2RH1 (113), PDB entry 2R4S (114)]; (2) active

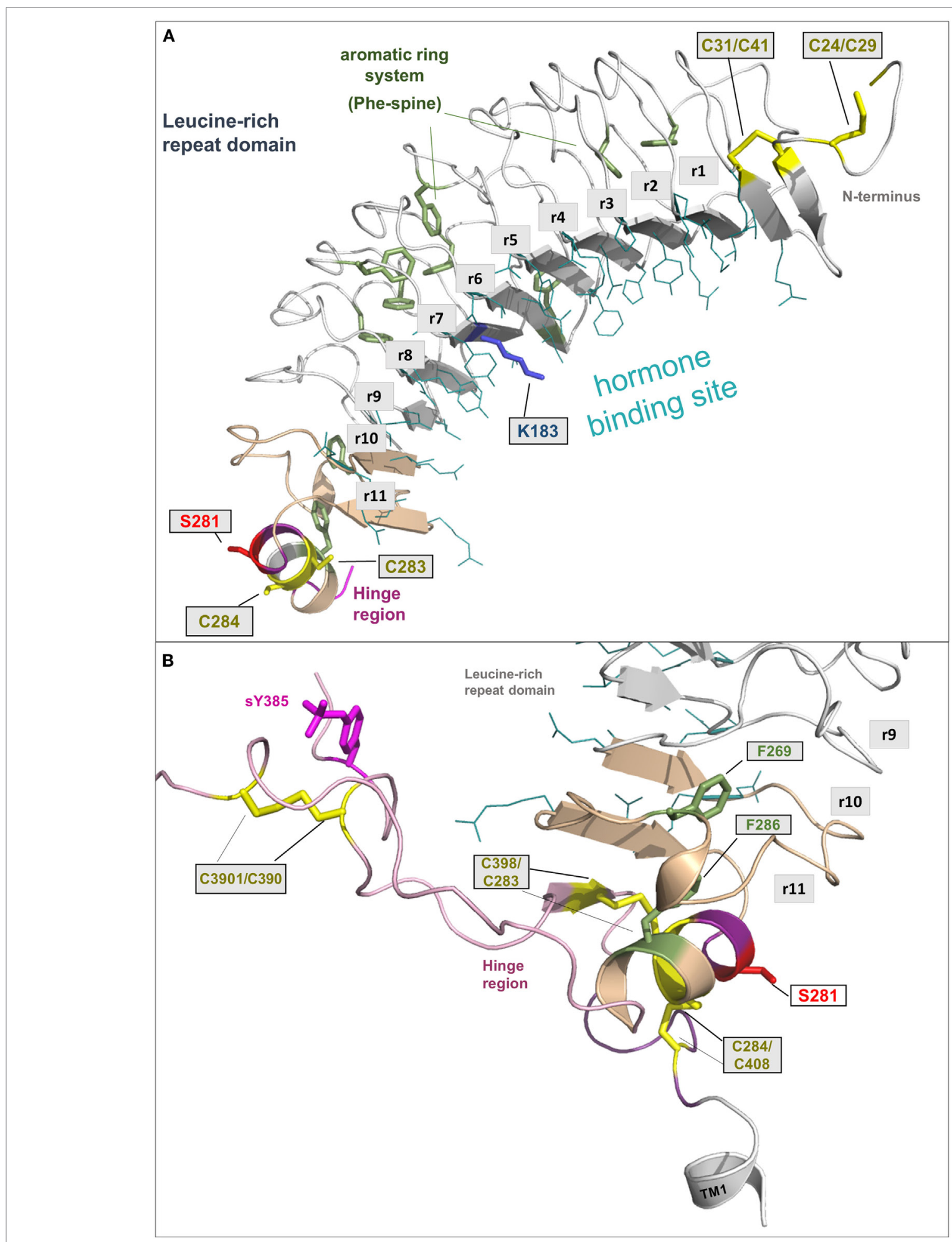

FIGURE $3 \mid$ Continued 


\section{FIGURE 3 | Continued}

A full-length model of the thyroid-stimulating hormone receptor (TSHR) leucine-rich repeat domain and a fragmental model of the hinge region.

(A) The LRRD of the TSHR is the main binding site for hormones and autoantibodies. They interact with amino acids in the concave site of this domain, which is arranged as a beta-sheet. Hydrophobic amino acid side chains are located mainly in the inner core of the domain, thus aromatic interactions are of high importance. Although the so far solved TSHR LRRD structures are constituted by a maximum of 9 repeats $(56,57)$, it was suggested $(53)$ that this domain is actually constituted by 11 repeats ( $r 1-r 11)$-as also presented here in this model (designed by a chimeric model-approach, LRRD model comprises amino acids 24-288). In contrast to other known LRRD structures with similarity to the glycoprotein hormone receptor (GPHR) LRRDs (66-68), the backbone on the convex side of this domain shows only one short helical structure namely in repeat 11 . The cysteines at positions 283 and 284 are known to interact with two cysteines at the C-terminal hinge region (B). Furthermore, mutations of serine 281 were identified as pathogenic $(70,71)$ and causing a gain of function by constitutive receptor activation. Of note, lysine 183 in repeat 7 (blue stick) was identified to be highly responsible for ligand specificity. The Lys183Arg substitution leads to a hypersensitivity for choriogonadotropin $(74,75)$. (B) This fragmental TSHR hinge region model (lilac-purple, amino acids 289-304 and 382-409) is adapted according to the solved follicle-stimulating hormone receptor (FSHR) ectodomain (ECD)/FSH complex structure (65) and contains several amino acids of high structural and functional importance. The cysteine 398 is located in a small beta-strand that is arranged parallel to the last beta-strand 11 of the LRRD. The two essential disulfide bridges Cys283/Cys398 and Cys284/Cys408 are shown. A third extracellular disulfide bridge between Cys301 and Cys390 stabilizes the interplay between the N-and C-terminus. Moreover, the recent FSHR ECD crystal structure bound with follitropin provided details for the first time on the second hormone-binding site of GPHRs around a conserved sulfated tyrosine (in TSHR sTyr385). This tyrosine binds into a pocket between the hormone subunits and contributes to ligand-binding properties (76).

conformations-opsin [PDB entry 3CAP (115)], opsin in complex with a C-terminal-binding peptide derived from the Gt-protein [PDB entry 3DQB (116)] or active metarhodopsin II (PDB entries 3PXO or 3PQR) (117), the beta-2 adrenergic receptor in complex with agonist and Gs-protein [PDB entry 3SN6 (118)], or the Adenosine-2A receptor in complex with an agonist and a mini-Gs protein [PDB entry 5 G53 (119)]. The particular template selection was made based on the specific purpose of the models-like simulation of an inactive versus active conformation [e.g., Ref. (120)] and based on general or local sequence similarities. In the past decade, a large number of new crystal structures from diverse GPCRs were solved, including further aminergic receptors, chemokine, peptidic, or fatty acid receptors [reviewed in Ref. (102) and collected under http://gpcrdb.org/structure $(121,122)]$. Consequently, this provokes the question as to what is currently the best structural template to model the SD or the entire structure of TSHR. Based on the overall sequence similarity, the closest single template for modeling the SD of TSHR is the beta-2 adrenergic receptor. However, primary sequence similarity to one single structural template may not be the best option. It is now common to build homology models using not only one template but using several template fragments in order to achieve maximum overlap of individual structural features, e.g., helical kinks or helical length dimensions $(103,123)$. Actually the TSHR has some of these specific structural properties related to amino acid fingerprints, which are not common in class A GPCRs. They are of high importance for an accurate model, and therefore they are also helpful to estimate the best modeling template. We will therefore extract and describe here a few significant examples important for defining structural properties of the TSHR, and we will also provide an inactive state model that is based on a "multi-fragment" approach (123).

One striking difference between the transmembrane helix (TMH) domain of most other class A GPCRs and the TSHR is that class A GPCRs typically contain a highly conserved proline in position $5 \times 50$ [modified Ballesteros and Weinstein nomenclature (124) considering structural alignments of bulges (125)] of TMH5, which is responsible for a bulged TMH5 conformation that causes a kink and twist toward the extracellular end of this helix. However, in the TSHR, there is an alanine (Ala593) in the corresponding position instead of a proline. Based on modeling approaches and mutant studies, in 2011 we suggested that an alanine at position $5 \times 50$ in TSHR causes a regular and stable alpha-helical conformation instead of a proline-supported bulge and kink in TMH5 (126). This structural prediction was later confirmed in crystal structures of receptors that do not have a proline at position $5 \times 50$ and which do indeed have a regular alpha-helical TMH5 such as the Sphingosine 1-phosphate receptor 1 [alanine in position $5 \times 50$; PDB entry $3 \mathrm{~V} 2 \mathrm{~W}$ (127)], the $\mathrm{P} 2 \mathrm{Y} 12$ receptor [asparagine in position $5 \times 50$; PDB entry $4 \mathrm{NTJ}$ (128)], and the lysophosphatidic acid receptor 1 [threonine in position $5 \times 50$, LPAR1, PDB entry $4 Z 34$ (129)]. These structural implications for Ala593 in TMH5 of TSHR (126) were recently confirmed by others (104).

Moreover, a methionine (Met637) in TMH6 of TSHR is also a specific feature of this receptor because at the corresponding position $(6 \times 48)$ the majority of class A GPCRs have a highly conserved tryptophan. Replacement of Met637 by a tryptophan led to constitutive activation, indicating a different or altered side chain adjustment at this position in the TSHR (106). Homology models must be built by incorporation of these special functional-structural characteristics, ideally by using structures with the exact match in the respective property. The TMH5-TMH6 arrangement but also that between TMH3 and TMH5 are key features and should be significant for functionalities like the high basal signaling activity of the TSHR (130) or the huge amount of known constitutively activating TSHR mutations (26), whereby these structural features should predestine the TSHR for constitutive activation just by slight amino acid alterations.

To build the most accurate models with implementation of these specific features, a fragment-based modeling approach was developed, whereby templates are selected separately for each TMH and helix 8 using sequence fingerprint motifs and sequence similarity scores (103). The general aim was to select "bestchoice" templates based on a logical decision tree or algorithm. This initial idea was transferred into a web server and database [GPCR-Sequence-Structure-Feature-Extractor $(\mathrm{SSFE})^{1}$ ] to provide the tool to the larger community (123). This initial database contained pre-calculated models for more than 5,000 class A

${ }^{1}$ http://www.ssfa-7tmr.de/ssfe. 
GPCRs (also including different species), but most importantly, this tool generates homology models and structural predictions for sequences of interest uploaded by the user. This method has recently been updated to include all 27 currently available inactive class A GPCR crystal structures for template selection and homology modeling. ${ }^{2}$

The inactive TMH model of TSHR generated during this recent update selected 6 of the 27 different template structures for model building (Table 1). Selecting transmembrane helices from different structural templates has the advantage that sequence differences causing slight backbone changes such as bulges or kinks are considered in more detail. Thus compared to using a single template, the multiple fragment approach can achieve an improved accuracy in the predicted models, which is essential for docking of small molecules or virtual screening. The reasons and fingerprint motifs for selecting particular TMH templates for the multiple fragment TSHR model are given in Table 1. For example, the conformation of TMH2 is based on TMH2 from ACM4 receptor (PDB entry 5DSG) since it contains (like TSHR) the fingerprint motif DXXXG at positions $2 \times 50$ to $2 \times 54$ and has the highest sequence similarity of similarly scoring templates. TMH3 of TSHR is based on TMH3 of AA2AR (PDB entry $4 \mathrm{EIY}$ ) because of the matching fingerprint Gly-Cys at positions $3 \times 24$ and $3 \times 25$. TMH5 is based on TMH5 of LPAR1 (PDB entry 4Z34), since like TSHR, there is not only no proline in position $5 \times 50$ but also no Phe in position $5 \times 47$ and an Asn at that position instead. Three different templates OX1R (PDB entry 4ZJ8), OX2R (PDB entry 4S0V), and P2Y12 (PDB entry 4NTJ) score most highly for TMH6 and are suggested for modeling this helix. We selected the model using human orexin receptor type 1 (OX1R_HUMAN) for further analysis due to it having the highest number of motifs matched and having the best resolution for the X-ray structure. Thus, the resulting TSHR model contains distinct kinks in TMHs 2 and 6 and a straight TMH5 due to the matched fingerprint motifs in these helices (Figure 4A).

${ }^{2}$ http://www.ssfa-7tmr.de/ssfe2.
Figure $4 \mathrm{~B}$ shows a comparison between this multiple fragment model with the best matching single template TSHR model based on the ADRB2 [PDB entry 2RH1 (114)]. The single template model differs not only by additional bulges in TMH2 and 5 and in the orientation of the highly conserved cysteine in TMH3 but also in orientations of the side chains Val421 (position $1 \times 39$ ) and Leu587 (position 5×44) (Figure 4B). Conservative mutations at these positions to isoleucine and valine, respectively, cause constitutive activation (104) and is thus incompatible with them being orientated toward the membrane as observed in the single template TSHR model (Figure 4B). However, the activating roles of these mutations are rationalized by the structural data when these side chains point toward neighboring helices (and thus potential interaction partners), as is observed in the multiple fragment TSHR model (colored in gray in Figure 4B). This clearly demonstrates the advantage of the multiple fragment approach in achieving an improved accuracy in the predicted SD models. Along these lines, recently 16 inactive crystal structures were used to generate multiple-template SD models of the TSHR utilizing another strategy (131). In their approach, Modeller (132) was used to build an averaged model of the TSHR SD by automatically combining all templates.

This also includes the intra- and extracellular loops. For adjusting the extracellular loops of TSHR models, different approaches have been used. SSFE integrated Superlooper2 (133), while others used Monte Carlo refinements (134) and Rosetta protocols (135) for TSHR loop modeling.

The SD model in an active state TSHR conformation can be built on the helix arrangement as observed in the crystal structures of opsin (116), metarhodopsin II (117), adenosine 2A receptor (119), or the beta-2 adrenergic receptor (118), where a huge outward tilt movement of $\sim 8-14 \AA$ of TMH6 were observed compared to the inactive state conformation [e.g., reviewed in Ref. $(136,137)]$. The beta-2 adrenergic receptor crystal structure complexed with agonist and Gs-protein (PDB entry 3P0G) served as a template to build the TSHR active state SD model. However, additional TSHR-relevant fingerprints of TMH conformations (described above) were considered while modeling for TMH2 (kink but no bulge) and TMH5 (straight helix).

TABLE 1 | Template fragments from different G-protein-coupled receptor crystal structures used for building an inactive homology model of the serpentine domain of thyroid-stimulating hormone receptor.

\begin{tabular}{|c|c|c|c|}
\hline Helix & $\begin{array}{c}\text { Sequence } \\
\text { similarity (\%) }\end{array}$ & $\begin{array}{l}\text { Suggested transmembrane helix } \\
\text { (TMH) fragment template } \\
\text { (UniProt entry name-PDB code) }\end{array}$ & Reasons for template selection (fingerprints) \\
\hline $\mathrm{TMH} 1$ & 60 & ACM2_HUMAN-3UON & Highest sequence similarity \\
\hline $\mathrm{TMH} 2$ & 57 & ACM4_HUMAN-5DSG & DXXXG at position $2 \times 50$ to $2 \times 54$, highest sequence similarity \\
\hline TMH3 & 53 & AA2AR_HUMAN-4EIY & GC at position $3 \times 24$ to $3 \times 25$ \\
\hline $\mathrm{TMH} 4$ & 50 & OPSD_TODPA-2Z73 & $P$ at position $4 \times 60$, highest sequence similarity \\
\hline TMH5 & 52 & LPAR1_HUMAN-4Z34 & No $\mathrm{P}$ at position $5 \times 50$, no $\mathrm{F}$ at position $5 \times 47, \mathrm{~N}$ at position $5 \times 47$, highest sequence similarity \\
\hline TMH6 & 47 & $\begin{array}{l}\text { OX1R_HUMAN-4ZJ8; OX2R_- } \\
\text { HUMAN-4SOV; P2Y12_HUMAN-4NTJ }\end{array}$ & $\begin{array}{l}\text { No FXXCWXP motif at position } 6 \times 44 \text { to } 6 \times 50 \text {, PXS at position } 6 \times 50 \text { to } 6 \times 52 \text {, highest sequence } \\
\text { similarity; no FXXCWXP motif at position } 6 \times 44 \text { to } 6 \times 50 \text {, PXS at position } 6 \times 50 \text { to } 6 \times 52 \text {, highest } \\
\text { sequence similarity; no FXXCWXP motif at position } 6 \times 44 \text { to } 6 \times 50 \text {, highest sequence similarity }\end{array}$ \\
\hline $\mathrm{TMH} 7$ & 50 & OPSD_TODPA-2Z73 & Highest sequence similarity \\
\hline H8 & 55 & AA2AR_HUMAN-4EIY & Highest sequence similarity \\
\hline
\end{tabular}

Reasons and fingerprint sequence motifs for selecting a particular TMH template are given. 


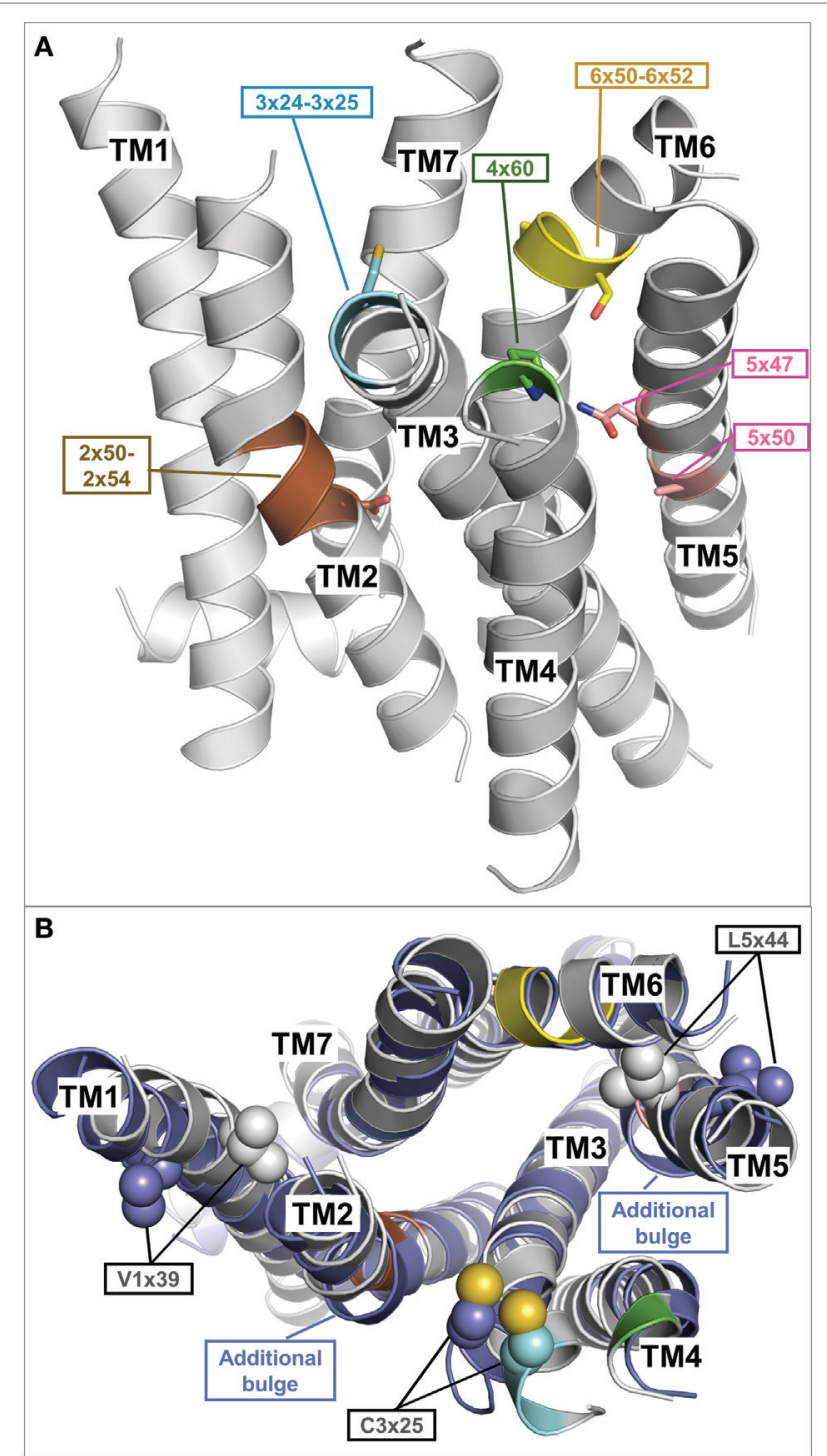

FIGURE 4 | Fragment-based thyroid-stimulating hormone receptor (TSHR) serpentine domain (SD) model with specific structural features. (A) This TSHR SD model was built from multiple transmembrane helix templates (see Table 1). The best matching fingerprint motifs between TSHR sequence and the selected template transmembrane helix $(\mathrm{TMH})$ fragment are highlighted and indicate a central kink motif for $\mathrm{TMH} 2$ (brown: DXXXG at position 2×50 to 2×54), an extracellular kink for TMH3 (cyan: Gly-Cys at position $3 \times 24$ to $3 \times 25$ ), an extracellular proline for $\mathrm{TMH} 4$ (green: $P$ at position $4 \times 60$ ), a regular central alpha helix for TMH5 (rose A5×50, $\mathrm{N} 5 \times 47$ ), and a strong kink for TMH6 (yellow modified FXXCWP motif at position $6 \times 44$ to $6 \times 50$, PXS at position $6 \times 50$ to $6 \times 52$ ). The remaining $\mathrm{TMH}$ templates were selected based on having the highest sequence similarity. (B) Comparison of the multiple-template fragment-based model (gray) with the best matching single template TSHR SD model based on the beta-2 adrenergic receptor (PDB entry 2RH1) (blue), which differs in additional bulges in $\mathrm{TMH} 2$ and 5 but also in orientations of the side chains V421 (position $1 \times 39$ ) and L587 (position 5×44). Constitutively activating mutations of both residues (104) are rationalized by the fragment-based model when these side chains point toward neighboring helices (gray), but are incompatible with them being orientated toward the membrane as observed in the single template TSHR model (blue).

\section{TSHR-Interacting Proteins-Hormones, Antibodies, G-Proteins, and Arrestin}

The TSHR is a hub for signal transduction between different cellular regions and transduces information from signal inducers (extracellular) toward intracellular signaling molecules. Taking the high number of different GPCRs and ligands into consideration [more than 800 in humans $(7,138)$ ], these ligand/GPCR(s)/effector systems are generally of high evolutionary success and importance (139). The physiological differentiation between particular GPCRs, their ligands, and resulting signaling in one cell or tissue are determined by time occurrence, cell-specific expression levels, ligand/ receptor selectivity, and spatial separation, which also holds true for the TSHR under physiological conditions. In addition, for TSHR-interacting proteins like the Gs-protein (140-142) or TSH $(143,144)$ pathogenic mutants are known. These facts, as well as in context to its interacting proteins makes it very interesting to study and describe the TSHR or to search for further potential interaction partners that are unknown so far. But what is currently known about TSHR-interacting proteins in bound or unbound conformations?

In Figure 5, we provide an overview of known TSHR interaction partners and respective available structural information. In brief, TSHR can interact extracellularly with:

i. TSH and thyrostimulin, but no direct structural information is yet available, only structural homology models can be designed based on similarity to existing crystal structures of FSH [PDB entries 1FL7 (145)-unbound state, 1XWD (64) and 4AY9 (65)-bound state] or CG [all structures are in unbound state, PDB entries 1HCN (146), 1HRP (147), 1QFW (148)] (see Figure 2).

ii. Blocking [PDB entry 2XWT (57)] or activating antibodies [PDB entry 3G04 (56)], direct structural information is available in bound conformations, and also the unbound structure of an (inverse agonistic) antibody is available [PDB entry 4QT5 (149)].

In the transmembrane region TSHR can constitute:

iii. Homodimers $(150,151)$, which can be modeled by using several different GPCR dimer structures (see also StructuralFunctional Aspects of TSHR Oligomerization), like from the $\mu$-opioid-receptor [MOR (152)], $\kappa$-opioid receptor [KOR (153)], opsin (115), chemokine receptor CXCR4 (154), or the $\beta$-adrenergic receptor 1 [ $\beta$-1AR (155)]. So far, it is unknown whether TSHR also constitutes functionally relevant heterodimers with other GPCRs, but it would be of enormous importance to clarify this question because heterodimerization could have dramatic consequences on TSHR functionalities as known from other GPCRs (156-160) and many different GPCRs are expressed in the same tissues as TSHR [e.g., searchable in Ref. (161)].

Intracellular interaction partners are:

iv. Arrestin, where bound complexes with opsin or rhodopsin are available [rhodopsin/arrestin PDB entries 4ZWJ (162), 


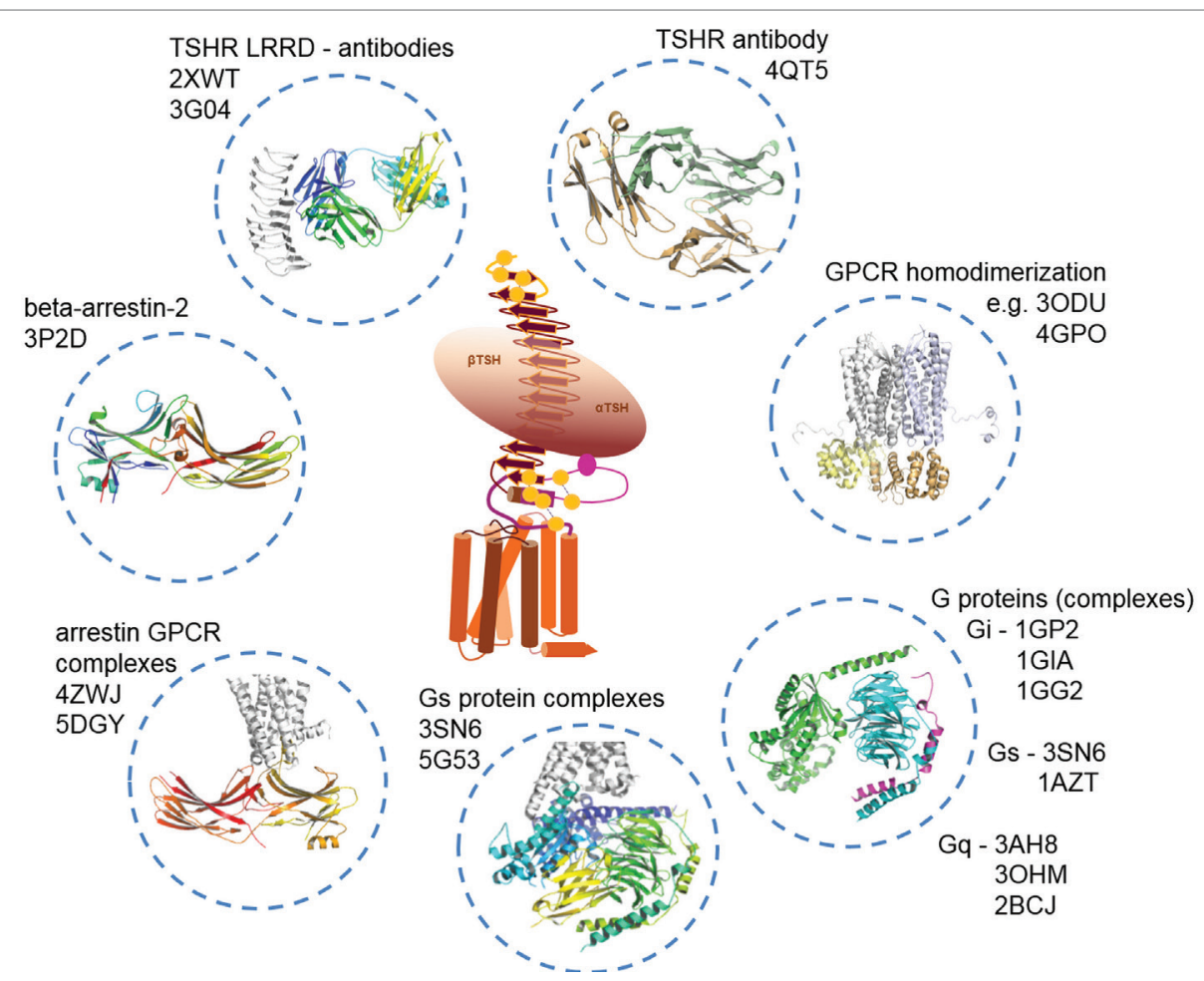

FIGURE 5 | Available structural information for thyroid-stimulating hormone receptor (TSHR) interaction partners. As shown in Figure 2, structural information on the TSHR is still limited. However, several interaction partners like autoantibodies (TSH is not solved so far), or Gi, Gs, and arrestin in bound and unbound conformations already have determined structures available. This knowledge can be used to construct larger model complexes as presented in

Figures 6,8 and 10.

5DGY (163)], and opsin/arrestin fragment [PDB entry 4PXF (164)], but also unbound arrestin structures were already determined [e.g., inactive state-PDB entry 3P2D (165)], or pre-active states [PDB entries 4J2Q and 4JQI $(166,167)]$.

v. Numerous crystal structures of unbound (inactive) G-protein subtypes have been solved, like for Gi [PDB entries 1GIA (168), 1GG2 (169)], Gs [PDB entry 1AZT (170)], and Gq [PDB entries 3AH8 (171), 3OHM (172), 2BCJ (173)]. Based on the beta-2 adrenergic receptor/Gs complex, a bound Gs conformation is also available [PDB entry 3SN6 (118)].

Thus, based on the above as well as the information from Figure 2, it is clear that a specific set of structural information is already available for TSHR and interacting proteins, intracellular and extracellular. Consequently, the available data enables two objectives:

1. The assembling between TSHR and interacting proteins as models of complexes.

2. The estimation of structural transitions between the unbound and bound states for TSHR as well as for the interacting partners.

However, it must also be concluded that much structural information is still missing, such as from the TSHR-binding hormones [TSH, thyrostimulin (174-176)], or TSHR structures themselves, or with bound allosteric ligands or intracellularly complexed partners. Moreover, combined with the missing information of the entire TSHR SD region or the full-length receptor with spatially adjusted domains, the molecular interpretation of functional data from mutagenesis studies or pathogenic findings is an approximation rather than a definitive answer so far. However, in the following section, we describe examples of feasible complex models, which are based on above described structures or homology models.

\section{Feasible TSHR and TSHR Complex Models}

At the moment, the gap in structural information can only be resolved by building homology models based on the aforementioned crystal structures (Figures 2, 3A,B, 5 and 9). By building individual and complexed homology models, insight into the TSHR SD, the differences between active and inactive structures or between bound and unbound properties of the interacting proteins can be gained. The principal idea of homology modeling is to adapt the already determined homologous structures and respective amino acid sequences (e.g., described in Section "TSHR-Interacting Proteins-Hormones, Antibodies, G-Proteins, and Arrestin") toward the targets of intereste.g., TSHR and TSH. This method is appropriate because the structural conservation and similarity of GPCRs is higher than their amino acid sequence similarity $(100,101,103)$. We used the structural information documented above (i.-v.) to design 


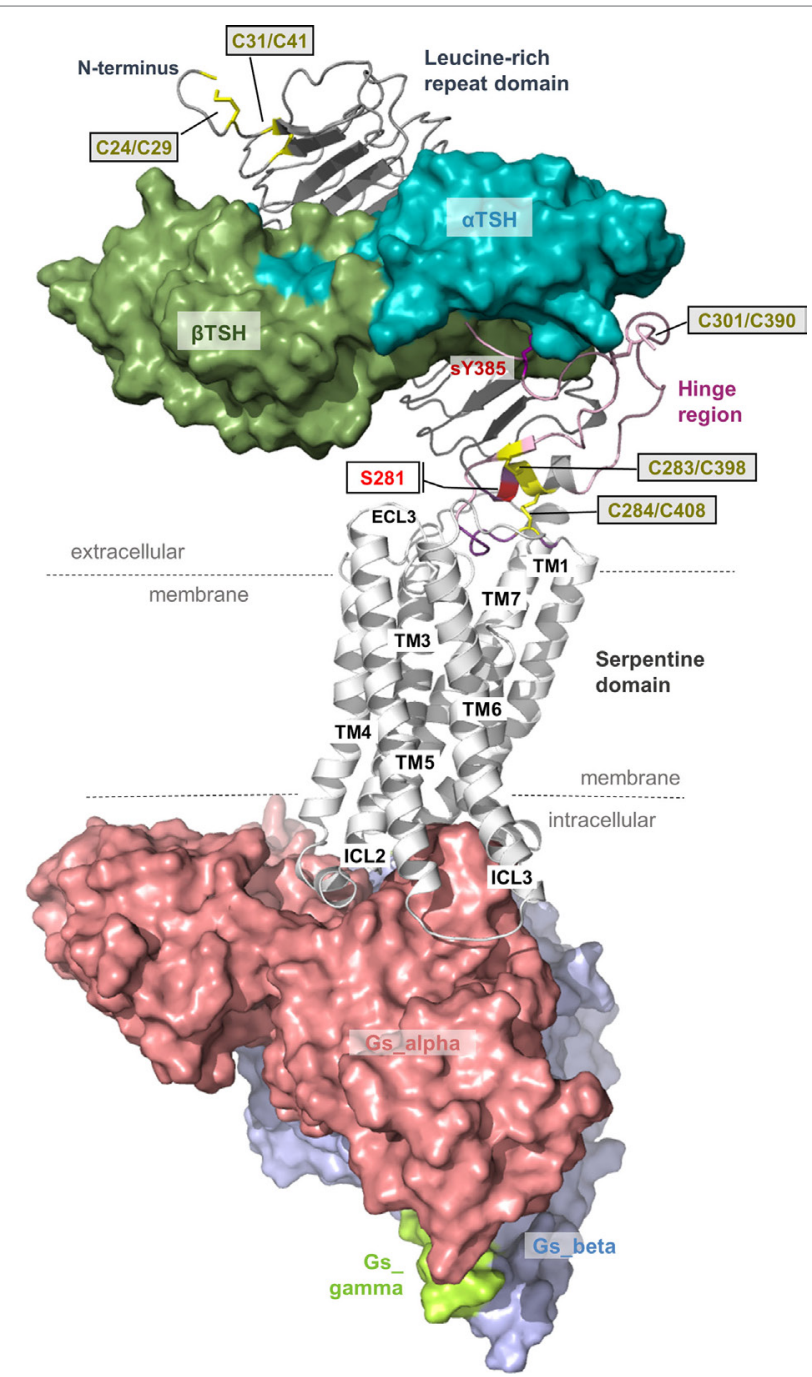

FIGURE 6 | A thyroid-stimulating hormone receptor (TSHR)/Gs complex model. The nearly completed complex model between TSHR-TSH and $\mathrm{Gs}$ in an active conformation can be assembled based on information summarized in Figures $\mathbf{2}$ and $\mathbf{3}$. TSH (or thyrostimulin) binds at two sites in the TSHR, called binding site I (LRRD) and binding site II (hinge region), of which several specific amino acids mediate the contact and specificity for the hormone. This model provides structural information according to the general TSHR scheme in Figure 1, including the detailed disulfide bridges at the extracellular part, localization of the hinge region, or justification of the Gs molecule at the active TSHR structure conformation [based on the beta-2 adrenergic receptor/Gs complex PDB entry 3SN6 (118)].

the following TSHR-related models in different activity-state conformations:

(1) The hormones TSH and thyrostimulin in bound and unbound conformations based on FSH (free and bound) or CG (unbound) (Figures 2, 6-8).

(2) The full-length TSHR LRRD based on the LRRDs of the TSHR and of FSHR ECD/FSH complexes-as ligand bound conformations (Figure 3).

(3) The LRRD in combination with the hinge region based on the FSHR ECD/FSH complex-active state conformation (Figures 3B and 6).

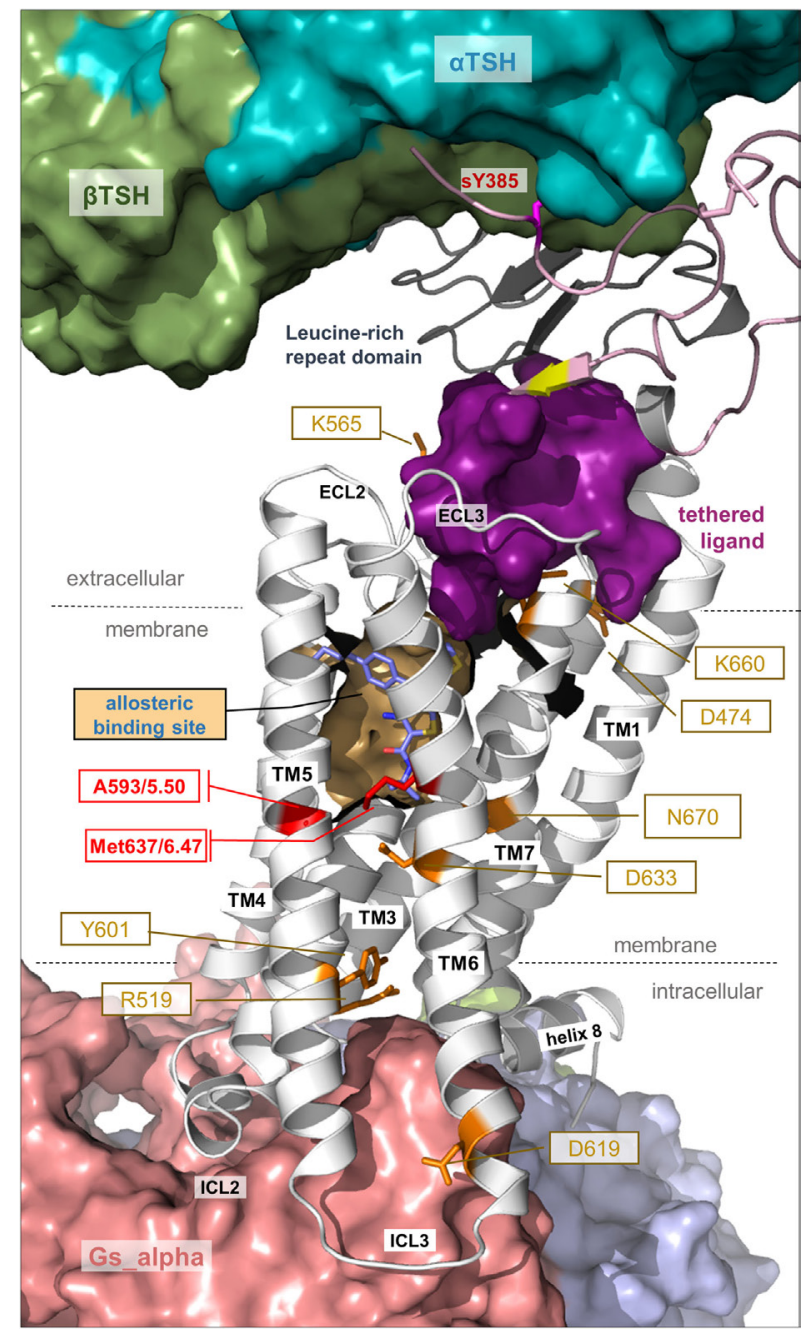

FIGURE 7 | Details of thyroid-stimulating hormone receptor (TSHR) structure and activation. This complex model visualizes important determinants and aspects of the TSHR activation mechanism. The hinge region links the LRRD with the serpentine domain and both parts harbor determinants for hormone binding. Ligand-binding triggers conformational changes at a convergent center between the LRRD and hinge region, thereby an inhibitory impact of the extracellular part on the receptor gets abrogated and an "intramolecular agonistic unit" or "tethered internal agonist" close to the transmembrane domain 1 becomes activated (violet surface). This extracellular signal induction is conveyed via structural rearrangements of the transmembrane-spanning helices toward the intracellular side. Several amino acids of high structural-functional relevance are involved in receptor activation (orange sticks) by maintaining specific activity-related conformations. They are localized at distinct spatial regions inside the TSHR, and they are interrelated with each other. The resulting active receptor conformation opens a spatial crevice for binding of intracellular interaction partners (Figures 6 and $\mathbf{8}$ ). Notably, the TSHR is characterized by specificities in the structural details such as a regular conformation of $\mathrm{TMH} 5$ compared to most other G-protein-coupled receptors (GPCRs), having an alanine instead of a proline at the $5 \times 50$ position, respectively. Moreover, the TSHR like all other glycoprotein hormone receptors (GPHRs) has a methionine at position 6×47 in TMH6, where usually a tryptophan is located in most class A GPCRs. In addition, it has been shown several times $(48,110,177)$ that the known allosteric-binding sites for small drug-like molecules acting on GPHRs are located between the transmembrane helices close to the extracellular loops, which is shown here exemplarily by a partial surface-pocket representation and a bound synthetic antagonist. 


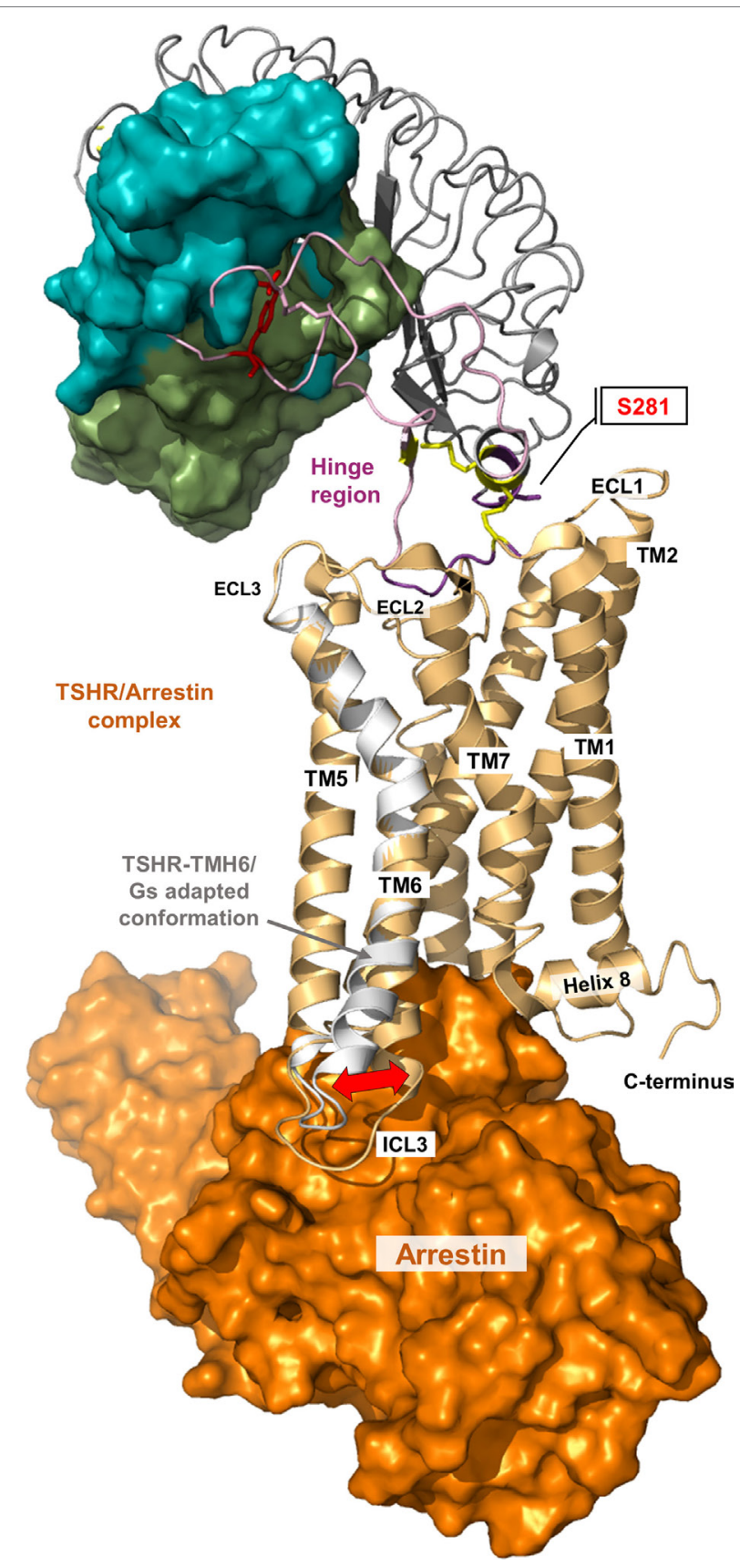

FIGURE 8 | A thyroid-stimulating hormone receptor (TSHR)/arrestin complex model. Binding and action of $\beta$-arrestin- 1 and $\beta$-arrestin- 2 on TSHR has already been reported (178-181). The putative structural conformation of TSHR adapted to this interacting protein is different to the TSHR/G-protein complex as shown in the presented superimposition of a TSHR/arrestin model (orange surface, complex is based on the crystallized rhodopsin/arrestin complexes PDB entries 4ZWJ, 5DGY) with the TMH6 conformation from the active TSHR/Gs complex (white backbone).

(4) The partial extracellular TSHR part bound with TSH or thyrostimulin based on the FSHR ECD/FSH complex (Figure 6).

(5) The TSHR extracellular part (LRRD and hinge region) bound with antibodies based on template chimeras between the solved LRRD/antibody complexes and the FSHR/ECD.
(6) TSHR SD in an inactive state (e.g., Figure 4) based on other GPCRs with determined structures.

(7) TSHR SD in active state conformations (e.g., Figures 6, 8 and 9) like from ADRB2 or opsin.

(8) Inactive or active state conformations with bound allosteric ligands (Figure 7).

(9) TSHR SD or full-length TSHR as homomers (in inactive or active states) based on solved dimer structures of other GPCRs like opsin or MOR (Figure 10).

(10) TSHR in complex with arrestin (active state, Figure 8).

(11) TSHR in complex with G-protein (active state, Figure 6).

(12) TSHR homomers in complex with intracellular effectors [assembled active state complex models (Figures 7 and 8) in superimposition with dimeric GPCR crystal structures (Figure 10)].

These models provide insights into the:

- the putative structure and domain composition (Figures 6-10); - hormone binding-related determinants (Figures 3 and 6);

- determinants of signal transduction at the extracellular region (Figures 3 and 7);

- constitution of the SD in different conformations (Figures 6-9);

- visualizing particular important amino acids for intramolecular signal transduction (Figures 7 and 9);

- TSHR-binding modes with G-protein or arrestin (Figures 6 and 8).

The models outlined above are advanced compared to the few experimentally determined TSHR structures yet they are only approximate models and not necessarily correct or precisely predictive. Functionally supportive data for assembling the SD and the extracellular region are rather rare $(135,189)$. More detailed methods for building these models are described in our own previous publications on the TSHR or other GPCRs [e.g., Ref. (53, 90, 91, 126, 189, 190)]. However, what can these models tell us or how can they help to visualize mechanisms of the TSHR? In the following sections, we will highlight several important insights related to regulation and action of the TSHR, which are strongly dependent on structural properties.

\section{SIGNAL TRANSDUCTION BY STRUCTURAL REORGANIZATION: THE TSHR AT WORK}

\section{Induction of Signaling in the Extracellular Region}

Induction of the endogenous signal transduction by the TSHR is triggered extracellularly by TSH (191) or thyrostimulin binding (174-176). The LRRD and the hinge region both harbor determinants for hormone binding [reviewed in Ref. $(36,63)$ ]. Additionally, one specific residue of high importance for TSH binding is a sTyr sTyr385 $(76,92)$ located in the C-terminal end of the hinge region (Figures $\mathbf{3}$ and $\mathbf{6}$ ). Further amino acids in the hinge region are involved in ligand binding, mainly characterized by negatively charged side chains (53, 192-194). Generally, the hinge region has a drastic influence on hormone binding, 


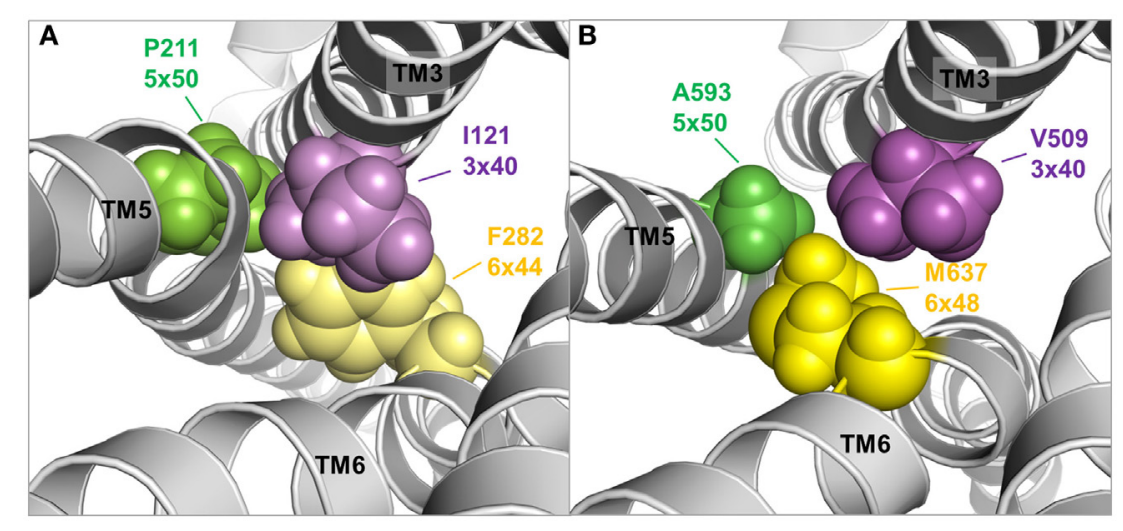

FIGURE 9 | TMH3-5-6 contact motif in the active state conformations of the beta-2 adrenergic receptor and an active state thyroid-stimulating hormone receptor (TSHR) model. A specific contact motif between residues in transmembrane helices 3, 5, and 6 is observed in the crystal structure of an active

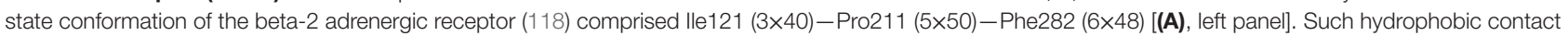
can also be found in the TSHR model comprised Val509 (3×40) - A593 (5×50) - Met 637 (6×48) [(B), right panel], although the amino acids differ. This contact motif is essential for triggering the active state in the TSHR.

structural constitution, and signal transduction, also in concert with the SD [e.g., Ref. (55, 195-201)].

From homology models of the TSHR (91) based on the crystal structure of the extracellular domain of FSHR (65), it was suggested that upon hormone or activating antibody binding a spatial displacement triggers conformational changes at a convergent center between the helical C-terminal end of the LRRD (pivotal helix) and the $\mathrm{N}$ - and $\mathrm{C}$-terminus of the hinge region (Figures 3 and 7). The hinge region flexibility agrees with later suggestions that interactions between negatively charged residues in the hinge region and positively charged residues in the LRRD of TSHR are released upon hormone activation (202), or with suggested charged-charged interactions between the LRRD (Glu251) and hinge region (55). From the same models in 2012 (91), it also became clear that serine 281 is located within the short helix at the junction between the LRRD and hinge region (Figure 6). From naturally occurring mutations and mutagenesis studies, this residue is known to be functionally significant (constitutive receptor activation) $(69,70,72,73)$. This serine has also been suggested to interact with the extracellular loop 1 (73), which was recently supported by cross-linking studies (135).

Notably, the hinge region has an inhibitory function on receptor activity as revealed by previous mutational studies (201, 203-205). In addition, it was shown in 2002 that the extracellular N-terminal TSHR part switches from a tethered inverse agonist to an internal agonist (173), although the precise determinants of both (eventually separated) functional units are still not clarified in their entirety because of a lack of experimental structural data. However, in 2004, it was found that the internal agonist comprises specific amino acids (Asp403-Asn406) in the C-terminal hinge region (189) and further experiments refined these insights on the intramolecular agonist unit $(196,200)$. A recent study with a peptide including Asp403-Asn406 showed that it can act agonistically (90), providing evidence that the internal agonist (assumed for all three GPHR subtypes) is located extracellularly close to TMH1 $(90,189,201)$. In conclusion, the
TSHR is characterized by a tethered ligand, which is not common in class A GPCRs, but has been described as a mechanism in several particular cases (206). Moreover, the internal agonist is very likely embedded in-between the extracellular loops of the SD $(90,189,201)$ and conveys the signal from the extracellular region toward the transmembrane domain (Figure 7 ). In this regard, it has been shown previously that the extracellular loops trigger the signal cooperatively (207).

\section{Signal Transport across the Transmembrane Domain}

Signal transduction by GPCRs is regulated by a specific rearrangement of particular helices to each other. But how does this process occur at the protein level and how is it regulated in the TSHR? Due to the lack of determined entire structures of the TSHR (and other GPHRs), the question arises how exactly does the extracellularly provided signal gives rise to helical movements. Generally, highly conserved amino acids in the class A GPCRs that are also found in the TSHR contribute to the maintenance of individual activity states and associated conformations by forming specific interactions. These interactions must be modified to facilitate helix movements and for new ones to occur after initial events to stabilize the active state conformation-in interplay with the ligand and the intracellular effector (208-211). It is known that the largest spatial movement related to GPCR activation affects TMH6 around a pivotal helix-kink at the highly conserved proline $6 \times 50(116,118)$. This key event must also be assumed to occur in the TSHR, which is supported by the fact that a huge number of constitutively activating mutants, particularly on TMH6, are known for the TSHR $(26,43)$.

Moreover, both above described TSHR specificities-the regular alpha-helical conformation of TMH5 and the tightly packed methionine 637 in TMH6-have impact on the hydrophobic helix-helix interfaces between TMH3-TMH5-TMH6, which are important for the transition between the active and inactive 

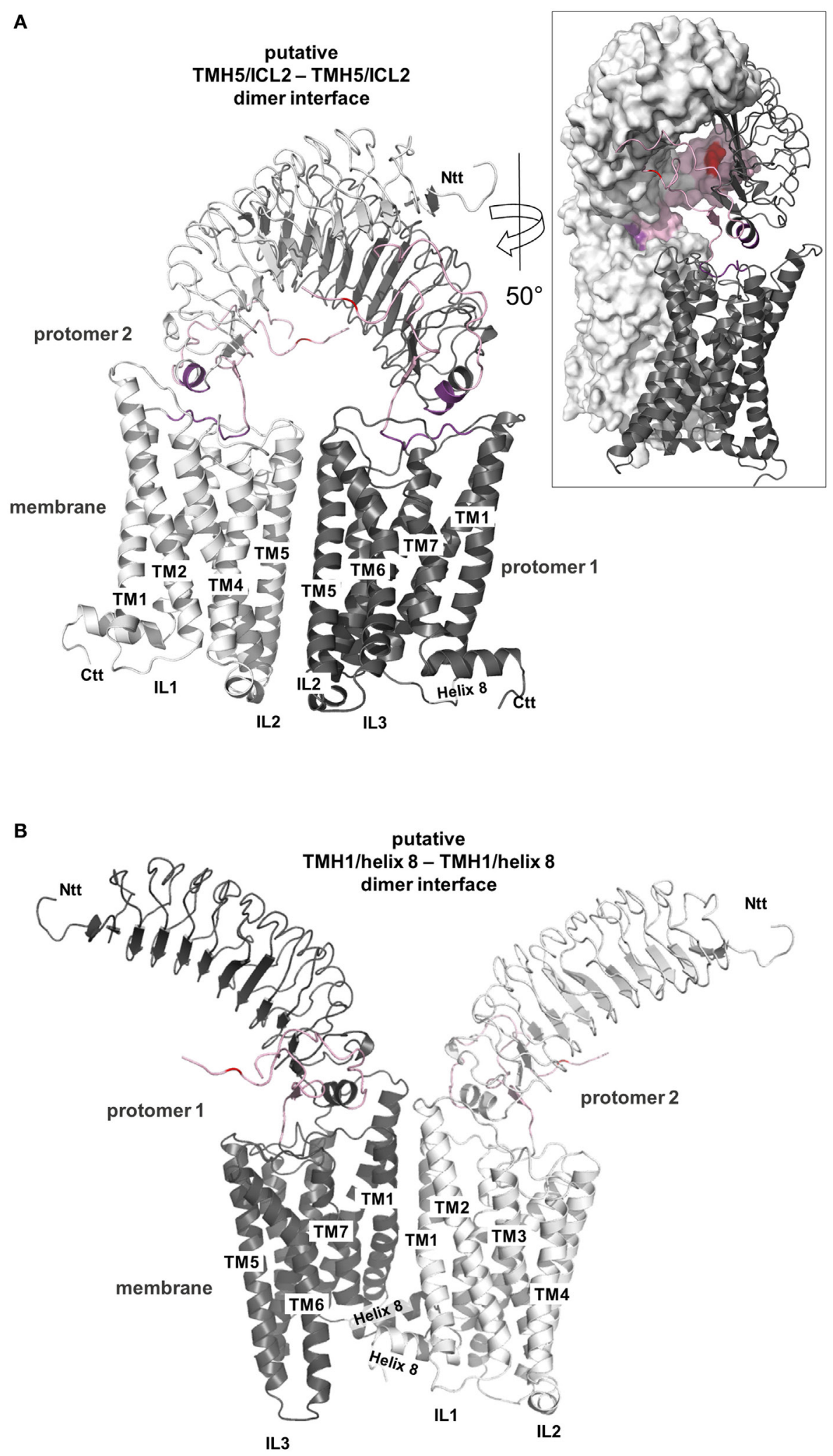

FIGURE 10 | Continued 
FIGURE 10 | Continued

Putative thyroid-stimulating hormone receptor (TSHR) dimer formations. A definitive TSHR homodimer interface still awaits experimental evidence but based on the available data it can be summarized that the serpentine domain has the main impact on dimer formation with the extracellular part also contributing (182-184). Already crystallized G-protein-coupled receptor (GPCR) homodimer arrangements are available [reviewed in, e.g., Ref. (185, 186)] and they point to three different potential arrangements between the receptor protomers, at: (I) TMH1-helix 8/TMH1-helix 8, (II) TMH5-TMH6/TMH5-TMH6, and (III) TMH4-ICL2/

TMH4-ICL2. These insights can be extrapolated to other GPCR oligomers assuming homology in sequence, structure, and mechanisms and using superimposition here we present two of these putative arrangements for a putative TSHR dimer constellation (150, 151, 187, 188) (entire homology model). In panel (A), a putative TMH5/ICL2-TMH5/ICL2 interface is shown based on the solved dimeric chemokine receptor CXCR4 [PDB entry 3ODU (154)], and in panel (B), a putative arrangement of the protomers with a TMH1/helix 8-TMH1/helix 8 interface is presented based on the opsin-dimer [PDB entry 3CAP (115)]. Both arrangements are feasible and also might occur simultaneously (e.g., in oligomers). In panel (A), the extracellular parts of both protomers get sterically close (see insert with partial surface representation) and hormone binding would need a rearrangement of this extracellular constellation. In panel (B), a symmetric TMH1-helix 8 interface hormone binding would not be influenced by the protomer arrangement.

state conformation. This is supported by previous studies where a hydrophobic interaction between TMH5 and TMH3 of the TSHR was analyzed by a complementary double mutant Val509Ala/ Ala593Val (Val509, TMH3, 3×40; Ala593, TMH5, 5×50) (212). This double mutant led to a functional rescue of the respective single-mutant dysfunctions and provided evidence for a direct hydrophobic interaction of these TMH3 and TMH5 residues. This finding is strongly supported by crystal structures of other GPCRs in the inactive and active state conformation, where an inward movement of proline (in the corresponding position $5 \times 50)$ toward TMH3 and 6 is observed for the active state such as for the beta-2 adrenergic receptor [ADRB2 (118)] or mu-opioid receptor [MOR (213)], thereby three hydrophobic residues of the ADRB2 located (i) on TMH5 (Pro211, 5×50), (ii) on TMH3 (Ile121, 3×40), and (iii) on TMH6 (Phe282, 6×44) interact tightly as a hydrophobic patch and contribute to the network of interactions that stabilize the active state conformation (Figure 9A). This spatial arrangement of the three hydrophobic residues was termed "PIF motif" or "contact motif" (210). Agonist binding induces these tightly packed hydrophobic interactions resulting in a rotation of TMH6, with a consequent outward tilt movement of the cytoplasmic helical end (Figure 8). Although the corresponding positions differ in sequence in the TSHR, a hydrophobic contact motif is also formed here by the aforementioned Ala593 $(\mathrm{TMH} 5,5 \times 50)$ together with Val509 $(\mathrm{TMH} 3,3 \times 40)$ and Met637 (TMH6, 6×48), which are subsequently also involved in the conformational active/inactive state transition (Figure 9B). This corresponds with constitutively activating mutations (CAMs) that were already identified at these TSHR positions [Ala593Asn (214), Val509Ala (212), and Met637Trp (106)].

But how are these modifications in the transmembrane region initiated or enabled? What we know is that the extracellular loops connect the helices (Figure 1) and it can be assumed that interactions occur between the TSHR hinge region and the extracellular loops $(73,201)$. They likely trigger the signal cooperatively toward the transmembrane region (207). In addition, specific loops or parts may also interact with the extracellular ends of certain helices as shown for the ECL2 and TMH6 in the TSHR (105). In conclusion, modifications of the loops can be transferred directly to interacting or connected helices, which are in line with reports in other GPCRs, where a salt bridge facilitates a link between the loops and receptor activation (215).

Second, signal transduction in the TSHR is not a single line of information flow but rather a multitude of synchronized sequences of events occurring. This assumption is made based on the fact that several previously reported inactivating or activating mutants at distinct amino acid positions are located at different receptor regions (Figure 7). Well investigated and significant examples are Lys660 in the TMH6/ECL3 transition (216), Lys565 in the ECL2 (105), Asp474 in TMH2 (217), or Glu409 in the transition between the hinge region and TMH1 (90) (Figure 7). Furthermore, Asp633 (TMH6) and Asn670 (TMH7) (107, 218, 219) are located in the central part of the domain core; and Tyr601 (220) or Asp619 $(221,222)$ is in the transmembrane region close to the intracellular site. In consequence and in contrast to the predominantly hydrophobic interfaces between TMH3-TMH5TMH6, the helix-helix interfaces between TMH3, TMH2, TMH6, and TMH7 are characterized by the occurrence of essential hydrophilic contacts, e.g., at the highly conserved positions Asp $2 \times 50$ or Asn $7 \times 50(107,219)$.

These hydrophilic contacts are complimented by conserved water molecules localized close to the mentioned conserved residues (103). Together, they constitute a network of intramolecular and water-mediated interactions (223) that are important for stabilizing GPCR structures by linking TMHs (224-226). Molecular dynamic simulations of class A GPCRs suggested an intrinsic water pathway, interrupted in the inactive state by hydrophobic layers of amino acid side chains, which change their conformation upon agonist binding leading to a continuous water channel. It is suggested that Tyr $7 \times 53$ of the NPXXY motif is of importance in this context (227). Receptor activation probably leads to a rearrangement and an extension of the water network [for example, Ref. $(90,107)]$ from the ligand-binding site to the cytoplasmic surface $(228,229)$, at least for specific GPCRs. As well as water, allosteric sodium has also been observed in antagonist/inverse agonist bound class A GPCR structures in a highly specific arrangement between TMH2 and TMH7 (224). During activation, the sodium pocket collapses and the ion translocate toward the cytoplasm. However, it seems that not all GPCRs possess this pocket, such as visual opsins which instead have ordered water molecules between Asp $2 \times 50$ and Tyr7×53 [PDB entry-4X1H (228)]. These observations underline the integral role of water molecules in GPCRs.

Apart from extracellular activation by its endogenous hormone ligands and autoantibodies, the TSHR signaling can be modulated by small-molecule ligands (SMLs) (52). Investigation of a potential allosteric-binding pocket for SMLs within the transmembrane domain (Figure 7) by modeling-driven mutagenesis led to the identification of distinct CAMs, including Val421Ile, Tyr466Ala, Thr501Ala, Leu587Val, Met637Cys, Met637Trp, 
Ser641Ala, Tyr643Phe, Leu645Val, and Tyr667Ala (106), and silencing mutations such as Val424Ile, Leu467Val, Tyr582Ala, Tyr582Phe, Tyr643Ala, and Leu665Val (230). These positions not only indicate key amino acids covering the allosteric-binding pocket of the TSHR but also positions where the TSHR conformation can be changed to an active or inactive state. Mapping these residues onto a structural model of TSHR indicates locations where SML agonists or antagonists enhance or impair signaling activity (231). These signaling sensitive amino acids are also compiled in the web-based resource "SSFA-GPHR" (41-44). ${ }^{3}$

\section{Intracellular Binding and Activation of Signaling Effectors}

All amino acids of the intracellular TSHR loops were already investigated by site-directed mutagenesis studies (111, 221, 232-235). Moreover, pathogenic mutations at these receptor parts were also identified in patients (236-239). These mutants and site-directed studies revealed that the entire set of the three ICLs and helix 8 contribute to induction of intracellular signaling by the TSHR, although differences concerning the impact on specific signaling pathways has been observed. Diverse activation pathways in class A GPCRs converge near the G-proteincoupling region (240). In principle, GPCR-mediated G-protein activation is characterized by structural shifts inside and between the G-protein subunits to each other, followed by exchange of GDP for GTP in the alpha-subunit and (partial) separation of the $\mathrm{G} \alpha$-from the $\mathrm{G} \beta \gamma$-subunits (241). This opens up interfaces to further contact partners (242). These events at the intracellular effector are induced by binding to the receptor in predisposition (without intracellular effector but with a bound agonist).

The intracellular effector can bind to the TSHR by fulfilling two criteria: (i) a spatial fit and (ii) an interaction surface that does not preclude binding, rather being supportive. So far, it is not known for GPCRs how exactly selectivity for a certain G-protein subtype is determined directly on the receptor. GPCRs with a preference for a particular G-protein subtype like Gs or Gq could not be allocated yet to a specific set of amino acids in the intracellular site. Additionally, receptor selectivity on the intracellular receptor site can be altered by making an amino acid substitution that repulses a specific effector (biased inactivation), and this is indeed the mechanism of several inactivating mutations in the intracellular TSHR loops, where, for instance, Gq activation is abolished but not activation of Gs [e.g., mutation Phe525Lys (243)]. This, in turn, would mean that selectivity is not associated with a complementary interaction pattern, it might be (theoretically) that selectivity in binding should be reached by a specific exclusion of effector subtypes due to small changes in the shape of the promiscuous receptor $G$ proteins binding interface.

What is known concerning binding of intracellular effectors to the TSHR? As noted above, a huge amount of functional data from amino acid substitutions in relation to G-protein activation (not for arrestin binding) is already available and based on these data first molecular models of a putative TSHR/Gq-protein complex were previously generated (111). This can now be extended

${ }^{3}$ http://www.ssfa-gphr.de. by incorporation of TSHR/Gs (Figure 6) and TSHR/arrestin (Figure 8) complex models based on recently determined structural complexes of other GPCRs [based on the beta-2 adrenergic receptor/Gs complex-PDB entry 3SN6 (118), or the rhodopsin/ arrestin complex-PDB entry 4ZWJ (162)]. The intracellular loop 1 (ICL1) contributes to G-protein binding but the amino acids have a different impact (111). Of particular interest is Arg450 at the transition between ICL1 and TMH2, where several cases of naturally occurring inactivating mutations were reported (244-247). Amino acid Arg450 may directly interact with G $\alpha$ as suggested by our homology model, e.g., with Gln390 in the C-terminal $\alpha 5$-helix of G $\alpha$ s (111). However, the middle part of the ICL1 is exclusively oriented toward the beta-subunit of the G-proteins and mutations in this region only decrease inositol phosphate (IP) generation, not cAMP accumulation (Leu440Ala, Thr441Ala, and His443Ala). Of note, it was reported for the MOR that initial interactions between the G-protein and intracellular loop 1 and helix 8 may be involved in G-protein coupling specificity and that TMH5/6 contribute later in the process of complex formation (248). This finding would be in general agreement with our suggestion that ICL1 is also involved in G-protein coupling by the TSHR.

In addition, the intracellular loop 2 (ICL2) is significantly involved in G-protein activation in the $\operatorname{TSHR}(221,243)$. Amino acids Met527, Arg528, and Asp530 are critical for both Gs and Gq activation, whereas alanine mutations of Ile523, Phe525, and Leu529 only impaired Gq-mediated signaling but not the Gs-mediated cAMP accumulation. Alanine mutations of Met527, Asp530, and Arg531 also caused impaired basal cAMP accumulation (120), which indicates involvement in Gs binding also in the basally active state conformation. Moreover, we suggest that the ICL2 conformation is helical (Figure 6) as supported by several crystal structures of diverse GPCRs, specifically in complexes $(118,162)$. In addition, the transitions between TMH5-ICL3TMH6 were identified as being important for G-protein activation, whereby single substitutions of Tyr605, Val608, Lys618, Lys621, and Ile622 selectively decrease Gq activation (220, 221). By contrast, mutations at Asp617 and Asp619 cause constitutive receptor activation for the Gs-mediated pathway $(218,221$, 239, 249).

Finally, these mutation-based studies at all three ICLs have shown that the binding modes between TSHR and Gs versus Gq do partially overlap, while completely inactivating mutations were only found for the receptor/Gq complex. The fact that Gq-mediated signaling, but not Gs-mediated cAMP accumulation, can be impaired by single side chain substitutions suggests that $\mathrm{Gq}$ binding is more fine-tuned than Gs binding. In strong relation to this might be the observed high basal activity for cAMP accumulation by TSHR, which is related to a permanent binding capacity and activation of Gs (130). The differences between $\mathrm{Gs}$ and $\mathrm{Gq}$ activation must be deciphered in more detail by determination of complex structures.

Moreover, so far, no experimental data from mutagenesis studies or structure determination are available concerning binding of arrestin to the activated TSHR, although arrestin binding is known to be of functional importance, e.g., for physically blocking further G-protein coupling and initiating the receptor 
shut-off (178-181). Activated GPCRs are phosphorylated by specific kinases on multiple sites at the C-terminus. In the inactive or basal state, arrestins are unable to bind activated TSHR, and interaction with several receptor-attached phosphates is critical for such an interaction. GPCR binding by arrestin is often discussed in terms of two events. Arrestin forms a low-affinity precomplex with the receptor, in which the phosphorylated receptor $\mathrm{C}$-terminus replaces the $\mathrm{C}$-tail of arrestin and thereby gains access to the high number of basic residues in the N-domain area (166, 167). C-tail displacement induces numerous conformational changes in key motifs and an overall domain rearrangement in arrestin that allow the second and tight-binding event of the activated receptor and the formation of a high-affinity complex. A key interaction of this high-affinity complex is the binding of the so-called finger loop region in arrestin to the intracellularbinding crevice of the activated receptor $(162,164)$, thereby the finger loop adopts a near helical structure and interacts with the highly conserved $E(D) R Y$ motif of the activated receptor. Remarkably, arrestin (namely, the near helical finger loop region) and G-protein (namely, the C-terminal alpha5 helix in the Galpha subunit) share a common binding crevice on the activated receptor (164). On the basis of the low-resolution crystal structure of peptide linker-fused rhodopsin-arrestin complex (162), a putative TSHR/arrestin complex model was created (Figure 8). The putative structural conformation particularly in TMH6 and ICL1-3 of TSHR adapted to this interacting arrestin model is slightly different to the TSHR/Gs-protein complex. However, until now, there are still many unanswered and unresolved questions due to the limited structural and biochemical knowledge of arrestin binding to GPHRs.

\section{Structural-Functional Aspects of TSHR Oligomerization}

Constitution of homo- and heteromers has been demonstrated for several members of different GPCR groups (250-253). Oligomerization is a biological tool for fine-tuning signaling and hence also physiological function (254-256), which is also relevant to endocrinology (257) and in pathological conditions (258-262). It is well documented that dimerization or oligomerization can have an impact on signaling properties as well as ligand binding $(263,264)$, signal transduction $(265,266)$, or cell-surface expression (267). Thus, oligomerization has been demonstrated to be a common and important feature of GPCRs including TSHR. What is known regarding TSHR oligomerization so far?

i. TSHR oligomerization $(150,151,187,188)$ occurs early in the endoplasmatic reticulum and is suggested to be crucial for proper receptor expression (268).

ii. TSHR probably forms higher order homomers rather than dimers (182) and the extracellular region participates in oligomerization, while the main protomer contact is most likely located at the transmembrane-spanning part (Figure 10) (183).

iii. A recent study revealed that two TSH molecules bound to a TSHR homodimer are required to activate not only Gs but also Gq (269). iv. It has been debated as to whether TSH influences dimer formation $(183,270)$. On the one hand, it was proposed that oligomeric TSHR rapidly dissociates into active monomers upon TSH binding (271). On the other hand, dimerization was found not to be affected by ligand binding (182).

v. Functionally dominant-negative effects have been shown for partially inactivating TSHR mutations (272). TSHR di- or oligomerization presents a molecular explanation as to why these TSHR mutations exhibit a phenotypic effect even in the heterozygous state of an inactivating mutation (273).

vi. By contrast, CAMs do not influence dimeric TSHR arrangements $(182,274)$.

One of the basic questions concerns TSHR oligomer organization from the structural perspective. Interfaces (contact-regions) between GPCR protomers were found under experimental conditions for different GPCRs, for instance, at the region of ICL2-TMH4 (275-277), TMH4-TMH5 (278), or TMH5-TMH5 (279-281). Most importantly, several crystal structures of dimeric GPCR complexes were determined, e.g., the $\mu$-opioidreceptor [MOR (152)], א-opioid receptor [KOR (153)], opsin (115), chemokine receptor CXCR4 (154), and the $\beta$-adrenergic receptor 1 [ $\beta$-1AR (155)]. Dimer interfaces are observed between TMH5-6, e.g., in the crystal structure of the CXCR4, or in the case of opsin, KOR, and $\beta-1 \mathrm{AR}$, the protomer interface is located between TMH1 and helix 8. Due to these repeated findings in the dimeric crystal structures, it can be postulated that class A GPCRs tend to have a preference to form protomer contacts at TMH1, helix 8, TMH5, and the ICL2-TMH4 transition.

Detailed characterization of TSHR oligomerization pointed to the SD as a main determinant for intermolecular receptorreceptor interplay and indicated that the extracellular receptor region might participate in this constellation (183, 184, 282). Recent studies suggested that the TMH1 is a main contact in the SD of the TSHR (283), which is in accordance with several of the crystallized GPCR interfaces reported above [e.g., the KOR dimer interface at TMH1-helix 8; PDB entry 4DJH (153)]. In line with this finding and with the published crystalized dimers, we provide molecular homology models of two putative TSHR dimer arrangements (Figure 10). In a putative symmetric TMH5-TMH5 interface, the TSHR would have additional side chain contacts at the extracellular side between TMH5 and TMH6 (Figure 10A). In a putative contact arrangement between TMH1-helix 8 (Figure 10B), TMH2 would contribute to the protomer contacts. A striking difference between both general orientations of the protomers is the relative orientation of the extracellular parts. Because it is so far unknown how the extracellular N-terminal LRRD and hinge region is arranged relative to the SD, the correct TSHR-TSHR constellation is unknown. According to our current homology models and arrangement of the ECD relative to the SD (Figure 6), a TMH5-TMH5 interface would result in sterical clashes between the extracellular parts and hormone binding would require initial structural modifications. In a TMH1-helix 8/TMH1-helix 8 protomer arrangement, the ECDs of both receptor molecules (models) would be freely accessible for the hormone molecules. In any case, it is reasonable to assume that both transmembrane interfaces occur simultaneously 
in higher order complexes of the TSHR [as observed for the $\beta-1 \mathrm{AR}$ (155)], which is probably functionally relevant for properties such as negative cooperativity in ligand binding caused by lateral intermolecular allosteric effects and/or negative intramolecular cooperative effects $(183,284)$.

Interestingly, the structure of the FSHR extracellular region with bound FSH was solved as a trimeric complex comprised three individual receptor/ligand units (49), while the previously solved FSHR/FSH complex with a shorter LRRD and without the hinge region (64) is a dimeric LRRD/hormone complex. Furthermore, in these two partial FSHR structures, interactions between the respective protomers are not similar, which might indicate flexibility in the arrangement or artificial constellations based on the crystallographic method. However, the trimericstructure organization for GPHRs should be kept as one of various options for a multimeric receptor organization, since it also fits to several functional data $(86,285)$.

\section{OPEN QUESTIONS AND FUTURE DIRECTIONS}

In summary, well-defined structural rearrangements and interaction events between different proteins accompanies and characterizes the TSHR activation process. Any modification such as substitution of interacting amino acids may affect the resulting signaling, which is supported by a huge number of naturally occurring mutations in addition to designed inactivating or activating receptor mutants (41-44). Many insights concerning the TSHR structure in relation to detailed and general functions were already identified. This information is useful for deciphering the mechanisms of signaling or pathogenic conditions at the molecular level. However, we also draw attention to the lack of structural information, meaning that the main open questions concern the entire receptor structure-with and without the "C-peptide," with interaction partners (arrestin or G-proteins) or the exact oligomer constitution. For instance, the bound TSH structure in

\section{REFERENCES}

1. Mussett MV, Perry WL. The international standard for thyrotrophin. Bull World Health Organ (1955) 13:917-29.

2. Libert F, Lefort A, Gerard C, Parmentier M, Perret J, Ludgate M, et al. Cloning, sequencing and expression of the human thyrotropin (TSH) receptor: evidence for binding of autoantibodies. Biochem Biophys Res Commun (1989) 165:1250-5. doi:10.1016/0006-291X(89)92736-8

3. Nagayama Y, Kaufman KD, Seto P, Rapoport B. Molecular cloning, sequence and functional expression of the cDNA for the human thyrotropin receptor. Biochem Biophys Res Commun (1989) 165:1184-90. doi:10.1016/0006291X(89)92727-7

4. Parmentier M, Libert F, Maenhaut C, Lefort A, Gerard C, Perret J, et al. Molecular cloning of the thyrotropin receptor. Science (1989) 246:1620-2. doi:10.1126/science. 2556796

5. Frazier AL, Robbins LS, Stork PJ, Sprengel R, Segaloff DL, Cone RD. Isolation of TSH and LH/CG receptor cDNAs from human thyroid: regulation by tissue specific splicing. Mol Endocrinol (1990) 4:1264-76. doi:10.1210/mend-4-8-1264

6. Misrahi M, Loosfelt H, Atger M, Sar S, Guiochon-Mantel A, Milgrom E. Cloning, sequencing and expression of human TSH receptor. Biochem Biophys Res Commun (1990) 166:394-403. doi:10.1016/0006-291X(90)91958-U

7. Fredriksson R, Lagerstrom MC, Lundin LG, Schioth HB. The G-proteincoupled receptors in the human genome form five main families. Phylogenetic complex with TSHR would be hugely beneficial for many TSHRrelated studies, including the improved directed development or refinement of medical therapeutics targeting the TSHR. Finally, the dynamic signaling process considering all known (and so far unknown) interaction partners resolved in time and cellular localization [also intracellularly $(180,181,286-290)$ ] would push the field enormously toward a comprehensive understanding of the TSHR, including suggested extra-thyroidal actions $(29,34$, 291-296).

\section{AUTHOR CONTRIBUTIONS}

All authors have worked together on the manuscript in a backand-forth procedure providing substantial contributions to the conception and interpretations. All authors have proofread the final version. In detail: GKleinau: conceptual contribution, major contribution to the content, generated homology models and their figures, and management of literature; CW: wrote modeling strategies especially for transmembrane domain modelling paragraphs, generated models and their corresponding figures, table, and checked English language; AK: wrote contributions about bioinformatics information resources and generated figures; HB: revised critical contributions about pathogenic and natural mutations of the TSHR; PM: wrote contributions about ligand binding and interaction; PS: wrote contributions concerning crystal structure interaction, especially concerning G-protein and arrestin interaction; GKrause: concept development, wrote and coordinated writing of the manuscript, and generated model figures.

\section{FUNDING}

This work was supported by the Deutsche Forschungsgemeinschaft (DFG), KR1273/4-2 to GKrause, BI 893/6-3 to HB, SFB740-B6 to PS, and DFG Cluster of Excellence "Unifying Concepts in Catalysis" (Research Field D3/E3-1) to PS.

analysis, paralogon groups, and fingerprints. Mol Pharmacol (2003) 63: 1256-72. doi:10.1124/mol.63.6.1256

8. Simoni M, Gromoll J, Nieschlag E. The follicle-stimulating hormone receptor: biochemistry, molecular biology, physiology, and pathophysiology. Endocr Rev (1997) 18:739-73. doi:10.1210/edrv.18.6.0320

9. Troppmann B, Kleinau G, Krause G, Gromoll J. Structural and functional plasticity of the luteinizing hormone/choriogonadotrophin receptor. Hum Reprod Update (2013) 19:583-602. doi:10.1093/humupd/dmt023

10. Vassart G, Pardo L, Costagliola S. A molecular dissection of the glycoprotein hormone receptors. Trends Biochem Sci (2004) 29:119-26. doi:10.1016/j.tibs. 2004.01.006

11. Postiglione MP, Parlato R, Rodriguez-Mallon A, Rosica A, Mithbaokar P, Maresca M, et al. Role of the thyroid-stimulating hormone receptor signaling in development and differentiation of the thyroid gland. Proc Natl Acad Sci U S A (2002) 99:15462-7. doi:10.1073/pnas.242328999

12. Trunnell JB, Rawson RW. The effect of thyroid stimulating hormone on the function of human normal and malignant thyroid tissue. JClin Endocrinol Metab (1948) 8:598.

13. Vassart G, Dumont JE. The thyrotropin receptor and the regulation of thyrocyte function and growth. Endocr Rev (1992) 13:596-611. doi:10.1210/er.13.3.596

14. Allgeier A, Offermanns S, Van Sande J, Spicher K, Schultz G, Dumont JE. The human thyrotropin receptor activates G-proteins Gs and Gq/11. J Biol Chem (1994) 269:13733-5. 
15. Laugwitz KL, Allgeier A, Offermanns S, Spicher K, Van Sande J, Dumont JE, et al. The human thyrotropin receptor: a heptahelical receptor capable of stimulating members of all four G protein families. Proc Natl Acad Sci U S A (1996) 93:116-20. doi:10.1073/pnas.93.1.116

16. Wiersinga WM. Graves' orbitopathy: management of difficult cases. Indian J Endocrinol Metab (2012) 16:S150-2. doi:10.4103/2230-8210.104026

17. Van Sande J, Raspe E, Perret J, Lejeune C, Maenhaut C, Vassart G, et al. Thyrotropin activates both the cyclic AMP and the PIP2 cascades in $\mathrm{CHO}$ cells expressing the human cDNA of TSH receptor. Mol Cell Endocrinol (1990) 74:R1-6. doi:10.1016/0303-7207(90)90209-Q

18. Buch TR, Biebermann H, Kalwa H, Pinkenburg O, Hager D, Barth H, et al. G13-dependent activation of MAPK by thyrotropin. J Biol Chem (2008) 283:20330-41. doi:10.1074/jbc.M800211200

19. Krause K, Boisnard A, Ihling C, Ludgate M, Eszlinger M, Krohn K, et al. Comparative proteomic analysis to dissect differences in signal transduction in activating TSH receptor mutations in the thyroid. Int J Biochem Cell Biol (2012) 44:290-301. doi:10.1016/j.biocel.2011.10.024

20. Latif R, Morshed SA, Zaidi M, Davies TF. The thyroid-stimulating hormone receptor: impact of thyroid-stimulating hormone and thyroid-stimulating hormone receptor antibodies on multimerization, cleavage, and signaling. Endocrinol Metab Clin North Am (2009) 38:319-41. doi:10.1016/j.ecl.2009.01.006

21. Kero J, Ahmed K, Wettschureck N, Tunaru S, Wintermantel T, Greiner E, et al. Thyrocyte-specific Gq/G11 deficiency impairs thyroid function and prevents goiter development. J Clin Invest (2007) 117:2399-407. doi:10.1172/JCI30380

22. Ledent C, Parmentier M, Maenhaut C, Taton M, Pirson I, Lamy F, et al. The TSH cyclic AMP cascade in the control of thyroid cell proliferation: the story of a concept. Thyroidology (1991) 3:97-101.

23. Verrier B, Fayet G, Lissitzky S. Thyrotropin-binding properties of isolated thyroid cells and their purified plasma membranes. Relation of thyrotropinspecific binding to adenylate-cyclase activation. Eur J Biochem (1974) 42: 355-65. doi:10.1111/j.1432-1033.1974.tb03347.x

24. Winkler F, Kleinau G, Tarnow P, Rediger A, Grohmann L, Gaetjens I, et al. A new phenotype of nongoitrous and nonautoimmune hyperthyroidism caused by a heterozygous thyrotropin receptor mutation in transmembrane helix 6 . J Clin Endocrinol Metab (2010) 95:3605-10. doi:10.1210/jc.2010-0112

25. Kohn LD, Saji M, Akamizu T, Ikuyama S, Isozaki O, Kohn AD, et al. Receptors of the thyroid: the thyrotropin receptor is only the first violinist of a symphony orchestra. Adv Exp Med Biol (1989) 261:151-209. doi:10.1007/978-14757-2058-7_7

26. Vassart G, Kleinau G. TSH receptor mutations and diseases. In: De Groot LJ, Beck-Peccoz P, Chrousos G, Dungan K, Grossman A, Hershman JM, et al., editors. Endotext. South Dartmouth, MA: MDTEXT.COM, INC. (2014). Available from: www.endotext.org

27. Bolonkin D, Tate RL, Luber JH, Kohn LD, Winand RJ. Experimental exophthalmos. Binding of thyrotropin and an exophthalmogenic factor derived from thyrotropin to retro-orbital tissue plasma membranes. J Biol Chem (1975) 250:6516-21.

28. Dobyns BM. Studies on exopthalmos produced by thyrotropic hormone; changes induced in various tissues and organs (including the orbit) by thyrotropic hormone and their relationship to exophthalmos. Surg Gynecol Obstet (1946) 82:609-18.

29. Fernando R, Atkins S, Raychaudhuri N, Lu Y, Li B, Douglas RS, et al. Human fibrocytes coexpress thyroglobulin and thyrotropin receptor. Proc Natl Acad Sci U S A (2012) 109:7427-32. doi:10.1073/pnas.1202064109

30. Stan MN, Bahn RS. Risk factors for development or deterioration of Graves' ophthalmopathy. Thyroid (2010) 20:777-83. doi:10.1089/thy.2010.1634

31. Wiersinga WM. Autoimmunity in Graves' ophthalmopathy: the result of an unfortunate marriage between TSH receptors and IGF-1 receptors? J Clin Endocrinol Metab (2011) 96:2386-94. doi:10.1210/jc.2011-0307

32. Smith BR, Hall R. Binding of thyroid stimulators to thyroid membranes. FEBS Lett (1974) 42:301-4. doi:10.1016/0014-5793(74)80751-9

33. Wolff J, Winand RJ, Kohn LD. The contribution of subunits of thyroid stimulating hormone to the binding and biological activity of thyrotropin. Proc Natl Acad Sci U S A (1974) 71:3460-4. doi:10.1073/pnas.71.9.3460

34. Davies TF, Ando T, Lin RY, Tomer Y, Latif R. Thyrotropin receptor-associated diseases: from adenomata to Graves disease. J Clin Invest (2005) 115:1972-83. doi:10.1172/JCI26031

35. Dumont JE, Lamy F, Roger P, Maenhaut C. Physiological and pathological regulation of thyroid cell proliferation and differentiation by thyrotropin and other factors. Physiol Rev (1992) 72:667-97.
36. Kleinau G, Neumann S, Gruters A, Krude H, Biebermann H. Novel insights on thyroid-stimulating hormone receptor signal transduction. Endocr Rev (2013) 34:691-724. doi:10.1210/er.2012-1072

37. Rapoport B, Chazenbalk GD, Jaume JC, McLachlan SM. The thyrotropin (TSH) receptor: interaction with TSH and autoantibodies. Endocr Rev (1998) 19:673-716. doi:10.1210/edrv.19.6.0352

38. Szkudlinski MW, Fremont V, Ronin C, Weintraub BD. Thyroid-stimulating hormone and thyroid-stimulating hormone receptor structure-function relationships. Physiol Rev (2002) 82:473-502. doi:10.1152/physrev.00031.2001

39. Gershengorn MC, Neumann S. Update in TSH receptor agonists and antagonists. J Clin Endocrinol Metab (2012) 97:4287-92. doi:10.1210/ jc.2012-3080

40. Latif R, Ali MR, Ma R, David M, Morshed SA, Ohlmeyer M, et al. New small molecule agonists to the thyrotropin receptor. Thyroid (2015) 25:51-62. doi:10.1089/thy.2014.0119

41. Kleinau G, Brehm M, Wiedemann U, Labudde D, Leser U, Krause G. Implications for molecular mechanisms of glycoprotein hormone receptors using a new sequence-structure-function analysis resource. Mol Endocrinol (2007) 21:574-80. doi:10.1210/me.2006-0309

42. Kleinau G, Kreuchwig A, Worth CL, Krause G. An interactive web-tool for molecular analyses links naturally occurring mutation data with threedimensional structures of the rhodopsin-like glycoprotein hormone receptors. Hum Mutat (2010) 31:E1519-25. doi:10.1002/humu.21265

43. Kreuchwig A, Kleinau G, Krause G. Research resource: novel structural insights bridge gaps in glycoprotein hormone receptor analyses. Mol Endocrinol (2013) 27:1357-63. doi:10.1210/me.2013-1115

44. Kreuchwig A, Kleinau G, Kreuchwig F, Worth CL, Krause G. Research resource: update and extension of a glycoprotein hormone receptors web application. Mol Endocrinol (2011) 25:707-12. doi:10.1210/me.2010-0510

45. Latif R, Realubit RB, Karan C, Mezei M, Davies TF. TSH receptor signaling abrogation by a novel small molecule. Front Endocrinol (2016) 7:130. doi:10.3389/fendo.2016.00130

46. Neumann S, Eliseeva E, McCoy JG, Napolitano G, Giuliani C, Monaco F, et al. A new small-molecule antagonist inhibits Graves' disease antibody activation of the TSH receptor. J Clin Endocrinol Metab (2011) 96:548-54. doi:10.1210/ jc. $2010-1935$

47. Neumann S, Huang W, Eliseeva E, Titus S, Thomas CJ, Gershengorn MC. A small molecule inverse agonist for the human thyroid-stimulating hormone receptor. Endocrinology (2010) 151:3454-9. doi:10.1210/en.2010-0199

48. Neumann S, Huang W, Titus S, Krause G, Kleinau G, Alberobello AT, et al. Small-molecule agonists for the thyrotropin receptor stimulate thyroid function in human thyrocytes and mice. Proc Natl Acad Sci U S A (2009) 106:12471-6. doi:10.1073/pnas.0904506106

49. Neumann S, Kleinau G, Costanzi S, Moore S, Jiang JK, Raaka BM, et al. A low-molecular-weight antagonist for the human thyrotropin receptor with therapeutic potential for hyperthyroidism. Endocrinology (2008) 149(12):594550. doi:10.1210/en.2008-0836

50. Neumann S, Nir EA, Eliseeva E, Huang W, Marugan J, Xiao J, et al. A selective TSH receptor antagonist inhibits stimulation of thyroid function in female mice. Endocrinology (2014) 155(1):310-4. doi:10.1210/en.2013-1835

51. Neumann S, Pope A, Geras-Raaka E, Raaka BM, Bahn RS, Gershengorn $\mathrm{MC}$, et al. antagonist inhibits thyrotropin receptor-mediated stimulation of cAMP production in Graves' orbital fibroblasts. Thyroid (2012) 22:839-43. doi:10.1089/thy.2011.0520

52. Neumann S, Raaka BM, Gershengorn MC. Human TSH receptor ligands as pharmacological probes with potential clinical application. Expert Rev Endocrinol Metab (2009) 4:669. doi:10.1586/eem.09.36

53. Kleinau G, Mueller S, Jaeschke H, Grzesik P, Neumann S, Diehl A, et al. Defining structural and functional dimensions of the extracellular thyrotropin receptor region. J Biol Chem (2011) 286:22622-31. doi:10.1074/jbc.M110.211193

54. Caltabiano G, Campillo M, De Leener A, Smits G, Vassart G, Costagliola S, et al. The specificity of binding of glycoprotein hormones to their receptors. Cell Mol Life Sci (2008) 65:2484-92. doi:10.1007/s00018-008-8002-9

55. Chen CR, McLachlan SM, Rapoport B. Thyrotropin (TSH) receptor residue E251 in the extracellular leucine-rich repeat domain is critical for linking TSH binding to receptor activation. Endocrinology (2010) 151:1940-7. doi:10.1210/ en.2009-1430

56. Sanders J, Chirgadze DY, Sanders P, Baker S, Sullivan A, Bhardwaja A, et al. Crystal structure of the TSH receptor in complex with a thyroid-stimulating autoantibody. Thyroid (2007) 17:395-410. doi:10.1089/thy.2007.0041 
57. Sanders P, Young S, Sanders J, Kabelis K, Baker S, Sullivan A, et al. Crystal structure of the TSH receptor (TSHR) bound to a blocking-type TSHR autoantibody. J Mol Endocrinol (2011) 46:81-99. doi:10.1530/JME-10-0127

58. Smits G, Campillo M, Govaerts C, Janssens V, Richter C, Vassart G, et al. Glycoprotein hormone receptors: determinants in leucine-rich repeats responsible for ligand specificity. EMBO J (2003) 22:2692-703. doi:10.1093/ emboj/cdg260

59. Nagayama Y, Nishihara E, Namba H, Yamashita S, Niwa M. Identification of the sites of asparagine-linked glycosylation on the human thyrotropin receptor and studies on their role in receptor function and expression. J Pharmacol Exp Ther (2000) 295:404-9.

60. Nunez Miguel R, Sanders J, Furmaniak J, Rees Smith B. Glycosylation pattern analysis of glycoprotein hormones and their receptors. J Mol Endocrinol (2017) 58(1):25-41. doi:10.1530/JME-16-0169

61. Oda Y, Sanders J, Roberts S, Maruyama M, Kiddie A, Furmaniak J, et al. Analysis of carbohydrate residues on recombinant human thyrotropin receptor. J Clin Endocrinol Metab (1999) 84:2119-25. doi:10.1210/jcem.84.6.5756

62. Russo D, Chazenbalk GD, Nagayama Y, Wadsworth HL, Rapoport B. Sitedirected mutagenesis of the human thyrotropin receptor: role of asparaginelinked oligosaccharides in the expression of a functional receptor. Mol Endocrinol (1991) 5:29-33. doi:10.1210/mend-5-1-29

63. Kleinau G, Krause G. Thyrotropin and homologous glycoprotein hormone receptors: structural and functional aspects of extracellular signaling mechanisms. Endocr Rev (2009) 30:133-51. doi:10.1210/er.2008-0044

64. Fan QR, Hendrickson WA. Structure of human follicle-stimulating hormone in complex with its receptor. Nature (2005) 433:269-77. doi:10.1038/ nature 03206

65. Jiang X, Liu H, Chen X, Chen PH, Fischer D, Sriraman V, et al. Structure of follicle-stimulating hormone in complex with the entire ectodomain of its receptor. Proc Natl Acad Sci U S A (2012) 109:12491-6. doi:10.1073/pnas. 1206643109

66. Enkhbayar P, Kamiya M, Osaki M, Matsumoto T, Matsushima N. Structural principles of leucine-rich repeat (LRR) proteins. Proteins (2004) 54:394-403. doi: $10.1002 /$ prot. 10605

67. Kobe B, Deisenhofer J. A structural basis of the interactions between leucinerich repeats and protein ligands. Nature (1995) 374:183-6. doi:10.1038/ $374183 \mathrm{a} 0$

68. Matsushima N, Tachi N, Kuroki Y, Enkhbayar P, Osaki M, Kamiya M, et al. Structural analysis of leucine-rich-repeat variants in proteins associated with human diseases. Cell Mol Life Sci (2005) 62:2771-91. doi:10.1007/s00018005-5187-z

69. Ho SC, Van Sande J, Lefort A, Vassart G, Costagliola S. Effects of mutations involving the highly conserved S281HCC motif in the extracellular domain of the thyrotropin (TSH) receptor on TSH binding and constitutive activity. Endocrinology (2001) 142:2760-7. doi:10.1210/en.142.7.2760

70. Duprez L, Parma J, Costagliola S, Hermans J, Van Sande J, Dumont JE, et al. Constitutive activation of the TSH receptor by spontaneous mutations affecting the N-terminal extracellular domain. FEBS Lett (1997) 409:469-74. doi:10.1016/S0014-5793(97)00532-2

71. Kopp P, Muirhead S, Jourdain N, Gu WX, Jameson JL, Rodd C. Congenital hyperthyroidism caused by a solitary toxic adenoma harboring a novel somatic mutation (serine281 - >isoleucine) in the extracellular domain of the thyrotropin receptor. J Clin Invest (1997) 100:1634-9. doi:10.1172/JCI1 19687

72. Ho SC, Goh SS, Li S, Khoo DH, Paterson M. Effects of mutations involving cysteine residues distal to the S281HCC motif at the C-terminus on the functional characteristics of a truncated ectodomain-only thyrotropin receptor anchored on glycosylphosphatidyl-inositol. Thyroid (2008) 18:1313-9. doi:10.1089/thy.2008.0240

73. Jaeschke H, Neumann S, Kleinau G, Mueller S, Claus M, Krause G, et al. An aromatic environment in the vicinity of serine 281 is a structural requirement for thyrotropin receptor function. Endocrinology (2006) 147:1753-60. doi:10.1210/en.2005-1138

74. Rodien P, Bremont C, Sanson ML, Parma J, Van Sande J, Costagliola S, et al. Familial gestational hyperthyroidism caused by a mutant thyrotropin receptor hypersensitive to human chorionic gonadotropin. N Engl J Med (1998) 339:1823-6. doi:10.1056/NEJM199812173392505

75. Smits G, Govaerts C, Nubourgh I, Pardo L, Vassart G, Costagliola S. Lysine 183 and glutamic acid 157 of the TSH receptor: two interacting residues with a key role in determining specificity toward TSH and human CG. Mol Endocrinol (2002) 16:722-35. doi:10.1210/mend.16.4.0815

76. Costagliola S, Panneels V, Bonomi M, Koch J, Many MC, Smits G, et al. Tyrosine sulfation is required for agonist recognition by glycoprotein hormone receptors. EMBO J (2002) 21:504-13. doi:10.1093/emboj/21.4.504

77. Jiang X, Dias JA, He X. Structural biology of glycoprotein hormones and their receptors: insights to signaling. Mol Cell Endocrinol (2014) 382:424-51. doi:10.1016/j.mce.2013.08.021

78. ChazenbalkGD, TanakaK,Nagayama Y,Kakinuma A,JaumeJC,McLachlanSM, et al. Evidence that the thyrotropin receptor ectodomain contains not one, but two, cleavage sites. Endocrinology (1997) 138:2893-9. doi:10.1210/en. 138.7.2893

79. Rapoport B, McLachlan SM. TSH receptor cleavage into subunits and shedding of the A-subunit; a molecular and clinical perspective. Endocr Rev (2016) 2016:23-42. doi:10.1210/er.2015-1098.2016.1.test

80. Couet J, de Bernard S, Loosfelt H, Saunier B, Milgrom E, Misrahi M. Cell surface protein disulfide-isomerase is involved in the shedding of human thyrotropin receptor ectodomain. Biochemistry (1996) 35:14800-5. doi:10.1021/ bi961359w

81. Loosfelt H, Pichon C, Jolivet A, Misrahi M, Caillou B, Jamous M, et al. Two-subunit structure of the human thyrotropin receptor. Proc Natl Acad Sci U S A (1992) 89:3765-9. doi:10.1073/pnas.89.9.3765

82. Misrahi M, Milgrom E. Cleavage and shedding of the TSH receptor. Eur J Endocrinol (1997) 137:599-602. doi:10.1530/eje.0.1370599

83. Quellari M, Desroches A, Beau I, Beaudeux E, Misrahi M. Role of cleavage and shedding in human thyrotropin receptor function and trafficking. Eur J Biochem (2003) 270:3486-97. doi:10.1046/j.1432-1033.2003.03718.x

84. Vassart G, Costagliola S. A physiological role for the posttranslational cleavage of the thyrotropin receptor? Endocrinology (2004) 145:1-3. doi:10.1210/ en.2003-1225

85. Mizutori Y, Chen CR, Latrofa F, McLachlan SM, Rapoport B. Evidence that shed thyrotropin receptor A subunits drive affinity maturation of autoantibodies causing Graves' disease. J Clin Endocrinol Metab (2009) 94:927-35. doi:10.1210/jc.2008-2134

86. Rapoport B, Aliesky HA, Chen CR, McLachlan SM. Evidence that TSH receptor A-subunit multimers, not monomers, drive antibody affinity maturation in Graves' disease. J Clin Endocrinol Metab (2015) 100:E871-5. doi:10.1210/ jc.2015-1528

87. Chazenbalk GD, Chen CR, McLachlan SM, Rapoport B. Does thyrotropin cleave its cognate receptor? Endocrinology (2004) 145:4-10. doi:10.1210/en. 2003-1002

88. Kaczur V, Puskas LG, Nagy ZU, Miled N, Rebai A, Juhasz F, et al. Cleavage of the human thyrotropin receptor by ADAM10 is regulated by thyrotropin. J Mol Recognit (2007) 20:392-404. doi:10.1002/jmr.851

89. Vu MT, Radu A, Ghinea N. The cleavage of thyroid-stimulating hormone receptor is dependent on cell-cell contacts and regulates the hormonal stimulation of phospholipase c. J Cell Mol Med (2009) 13:2253-60. doi:10.1111/ j.1582-4934.2008.00422.x

90. Bruser A, Schulz A, Rothemund S, Ricken A, Calebiro D, Kleinau G, et al. The activation mechanism of glycoprotein hormone receptors with implications in the cause and therapy of endocrine diseases. J Biol Chem (2016) 291:508-20. doi:10.1074/jbc.M115.701102

91. Krause G, Kreuchwig A, Kleinau G. Extended and structurally supported insights into extracellular hormone binding, signal transduction and organization of the thyrotropin receptor. PLoS One (2012) 7:e52920. doi:10.1371/ journal.pone.0052920

92. Bonomi M, Busnelli M, Persani L, Vassart G, Costagliola S. Structural differences in the hinge region of the glycoprotein hormone receptors: evidence from the sulfated tyrosine residues. Mol Endocrinol (2006) 20:3351-63. doi:10.1210/me.2005-0521

93. Bruysters M, Verhoef-Post M, Themmen AP. Asp330 and Tyr331 in the C-terminal cysteine-rich region of the luteinizing hormone receptor are key residues in hormone-induced receptor activation. J Biol Chem (2008) 283:25821-8. doi:10.1074/jbc.M804395200

94. Grzesik P, Kreuchwig A, Rutz C, Furkert J, Wiesner B, Schuelein R, et al Differences in signal activation by LH and hCG are mediated by the LH/ CG receptor's extracellular hinge region. Front Endocrinol (2015) 6:140. doi:10.3389/fendo.2015.00140 
95. Grzesik P, Teichmann A, Furkert J, Rutz C, Wiesner B, Kleinau G, et al. Differences between lutropin-mediated and choriogonadotropin-mediated receptor activation. FEBS J (2014) 281:1479-92. doi:10.1111/febs.12718

96. Deupi X, Kobilka B. Activation of G protein-coupled receptors. Adv Protein Chem (2007) 74:137-66. doi:10.1016/S0065-3233(07)74004-4

97. Deupi X, Standfuss J. Structural insights into agonist-induced activation of G-protein-coupled receptors. Curr Opin Struct Biol (2011) 21:541-51. doi:10.1016/j.sbi.2011.06.002

98. Hanson MA, Stevens RC. Discovery of new GPCR biology: one receptor structure at a time. Structure (2009) 17:8-14. doi:10.1016/j.str.2008.12.003

99. Katritch V, Cherezov V, Stevens RC. Diversity and modularity of G proteincoupled receptor structures. Trends Pharmacol Sci (2012) 33:17-27. doi:10.1016/j.tips.2011.09.003

100. Costanzi S. Homology modeling of class a $G$ protein-coupled receptors. Methods Mol Biol (2012) 857:259-79. doi:10.1007/978-1-61779-588-6_11

101. Costanzi S. Modeling G protein-coupled receptors and their interactions with ligands. Curr Opin Struct Biol (2013) 23:185-90. doi:10.1016/j.sbi.2013. 01.008

102. Costanzi S, Wang K. The GPCR crystallography boom: providing an invaluable source of structural information and expanding the scope of homology modeling. Adv Exp Med Biol (2014) 796:3-13. doi:10.1007/978-94-0077423-0_1

103. Worth CL, Kleinau G, Krause G. Comparative sequence and structural analyses of G-protein-coupled receptor crystal structures and implications for molecular models. PLoS One (2009) 4:e7011. doi:10.1371/journal.pone. 0007011

104. Chantreau V, Taddese B, Munier M, Gourdin L, Henrion D, Rodien P, et al. Molecular insights into the transmembrane domain of the thyrotropin receptor. PLoS One (2015) 10:e0142250. doi:10.1371/journal.pone.0142250

105. Kleinau G, Claus M, Jaeschke H, Mueller S, Neumann S, Paschke R, et al. Contacts between extracellular loop two and transmembrane helix six determine basal activity of the thyroid-stimulating hormone receptor. J Biol Chem (2007) 282:518-25. doi:10.1074/jbc.M606176200

106. Kleinau G, Haas AK, Neumann S, Worth CL, Hoyer I, Furkert J, et al. Signaling-sensitive amino acids surround the allosteric ligand binding site of the thyrotropin receptor. FASEB J (2010) 24:2347-54. doi:10.1096/fj. 09-149146

107. Urizar E, Claeysen S, Deupi X, Govaerts C, Costagliola S, Vassart G, et al. An activation switch in the rhodopsin family of $\mathrm{G}$ protein-coupled receptors: the thyrotropin receptor. J Biol Chem (2005) 280:17135-41. doi:10.1074/jbc. M414678200

108. Labadi A, Grassi ES, Gellen B, Kleinau G, Biebermann H, Ruzsa B, et al. Loss-of-function variants in a Hungarian cohort reveal structural insights on TSH receptor maturation and signaling. J Clin Endocrinol Metab (2015) 100:E1039-45. doi:10.1210/jc.2014-4511

109. Ringkananont U, Van Durme J, Montanelli L, Ugrasbul F, Yu YM, Weiss RE, et al. Repulsive separation of the cytoplasmic ends of transmembrane helices 3 and 6 is linked to receptor activation in a novel thyrotropin receptor mutant (M626I). Mol Endocrinol (2006) 20:893-903. doi:10.1210/ me.2005-0339

110. Moore S, Jaeschke H, Kleinau G, Neumann S, Costanzi S, Jiang JK, et al. Evaluation of small-molecule modulators of the luteinizing hormone/ choriogonadotropin and thyroid stimulating hormone receptors: structureactivity relationships and selective binding patterns. J Med Chem (2006) 49: 3888-96. doi:10.1021/jm060247s

111. Kleinau G, Jaeschke H, Worth CL, Mueller S, Gonzalez J, Paschke R, et al. Principles and determinants of G-protein coupling by the rhodopsin-like thyrotropin receptor. PLoS One (2010) 5:e9745. doi:10.1371/journal. pone.0009745

112. Palczewski K, Kumasaka T, Hori T, Behnke CA, Motoshima H, Fox BA, et al. Crystal structure of rhodopsin: a G protein-coupled receptor. Science (2000) 289:739-45. doi:10.1126/science.289.5480.739

113. Cherezov V, Rosenbaum DM, Hanson MA, Rasmussen SG, Thian FS, Kobilka TS, et al. High-resolution crystal structure of an engineered human beta2-adrenergic G protein-coupled receptor. Science (2007) 318:1258-65. doi:10.1126/science.1150577

114. Rasmussen SG, Choi HJ, Rosenbaum DM, Kobilka TS, Thian FS, Edwards PC, et al. Crystal structure of the human beta2 adrenergic G-protein-coupled receptor. Nature (2007) 450:383-7. doi:10.1038/nature06325
115. Park JH, Scheerer P, Hofmann KP, Choe HW, Ernst OP. Crystal structure of the ligand-free G-protein-coupled receptor opsin. Nature (2008) 454:183-7. doi:10.1038/nature07063

116. Scheerer P, Park JH, Hildebrand PW, Kim YJ, Krauss N, Choe HW, et al. Crystal structure of opsin in its G-protein-interacting conformation. Nature (2008) 455:497-502. doi:10.1038/nature07330

117. Choe HW, Kim YJ, Park JH, Morizumi T, Pai EF, Krauss N, et al. Crystal structure of metarhodopsin II. Nature (2011) 471:651-5. doi:10.1038/ nature09789

118. Rasmussen SG, DeVree BT, Zou Y, Kruse AC, Chung KY, Kobilka TS, et al. Crystal structure of the beta2 adrenergic receptor-Gs protein complex. Nature (2011) 477:549-55. doi:10.1038/nature10361

119. Carpenter B, Nehme R, Warne T, Leslie AG, Tate CG. Structure of the adenosine $\mathrm{A}(2 \mathrm{~A})$ receptor bound to an engineered $\mathrm{G}$ protein. Nature (2016) 536:104-7. doi:10.1038/nature18966

120. Kleinau G, Jaeschke H, Mueller S, Worth CL, Paschke R, Krause G. Molecular and structural effects of inverse agonistic mutations on signaling of the thyrotropin receptor - a basally active GPCR. Cell Mol Life Sci (2008) 65:3664-76. doi:10.1007/s00018-008-8450-2

121. Isberg V, Mordalski S, Munk C, Rataj K, Harpsoe K, Hauser AS, et al. GPCRdb: an information system for G protein-coupled receptors. Nucleic Acids Res (2016) 44:D356-64. doi:10.1093/nar/gkv1178

122. Munk C, Isberg V, Mordalski S, Harpsoe K, Rataj K, Hauser AS, et al. GPCRdb: the G protein-coupled receptor database - an introduction. $\mathrm{Br} J$ Pharmacol (2016) 173:2195-207. doi:10.1111/bph.13509

123. Worth CL, Kreuchwig A, Kleinau G, Krause G. GPCR-SSFE: a comprehensive database of G-protein-coupled receptor template predictions and homology models. BMC Bioinformatics (2011) 12:185. doi:10.1186/1471-2105-12-185

124. Ballesteros JA, Weinstein $\mathrm{H}$. Integrated methods for the construction of three-dimensional models and computational probing of structure-function relationships in G-protein coupled receptors. Methods Neurosci (1995) 25:366-428. doi:10.1016/S1043-9471(05)80049-7

125. Isberg V, de Graaf C, Bortolato A, Cherezov V, Katritch V, Marshall FH, et al. Generic GPCR residue numbers - aligning topology maps while minding the gaps. Trends Pharmacol Sci (2015) 36:22-31. doi:10.1016/j.tips. 2014.11.001

126. Kleinau G, Hoyer I, Kreuchwig A, Haas AK, Rutz C, Furkert J, et al. From molecular details of the interplay between transmembrane helices of the thyrotropin receptor to general aspects of signal transduction in family A G-protein-coupled receptors (GPCRs). J Biol Chem (2011) 286:25859-71. doi:10.1074/jbc.M110.196980

127. Hanson MA, Roth CB, Jo E, Griffith MT, Scott FL, Reinhart G, et al. Crystal structure of a lipid G protein-coupled receptor. Science (2012) 335:851-5 doi:10.1126/science.1215904

128. Zhang K, Zhang J, Gao ZG, Zhang D, Zhu L, Han GW, et al. Structure of the human P2Y12 receptor in complex with an antithrombotic drug. Nature (2014) 509:115-8. doi:10.1038/nature13288

129. Chrencik JE, Roth CB, Terakado M, Kurata H, Omi R, Kihara Y, et al. Crystal structure of antagonist bound human lysophosphatidic acid receptor 1. Cell (2015) 161:1633-43. doi:10.1016/j.cell.2015.06.002

130. Kleinau G, Biebermann H. Constitutive activities in the thyrotropin receptor: regulation and significance. Adv Pharmacol (2014) 70:81-119. doi:10.1016/ B978-0-12-417197-8.00003-1

131. Nunez Miguel R, Sanders J, Furmaniak J, Smith BR. Structure and activation of the TSH receptor transmembrane domain. Auto Immun Highlights (2017) 8:2. doi:10.1007/s13317-016-0090-1

132. Sali A, Blundell TL. Comparative protein modelling by satisfaction of spatial restraints. J Mol Biol (1993) 234:779-815. doi:10.1006/jmbi.1993.1626

133. Ismer J, Rose AS, Tiemann JK, Goede A, Preissner R, Hildebrand PW. SL2: an interactive webtool for modeling of missing segments in proteins. Nucleic Acids Res (2016) 44:W390-4. doi:10.1093/nar/gkw297

134. Ali MR, Latif R, Davies TF, Mezei M. Monte Carlo loop refinement and virtual screening of the thyroid-stimulating hormone receptor transmembrane domain. J Biomol Struct Dyn (2015) 33:1140-52. doi:10.1080/07391102.20 14.932310

135. Schaarschmidt J, Nagel MB, Huth S, Jaeschke H, Moretti R, Hintze V, et al. Rearrangement of the extracellular domain/extracellular loop 1 interface is critical for thyrotropin receptor activation. J Biol Chem (2016) 291: 14095-108. doi:10.1074/jbc.M115.709659 
136. Hofmann KP, Scheerer P, Hildebrand PW, Choe HW, Park JH, Heck M, et al. A G protein-coupled receptor at work: the rhodopsin model. Trends Biochem Sci (2009) 34:540-52. doi:10.1016/j.tibs.2009.07.005

137. Manglik A, Kobilka B. The role of protein dynamics in GPCR function: insights from the beta2AR and rhodopsin. Curr Opin Cell Biol (2014) 27: 136-43. doi:10.1016/j.ceb.2014.01.008

138. Fredriksson R, Schioth HB. The repertoire of G-protein-coupled receptors in fully sequenced genomes. Mol Pharmacol (2005) 67:1414-25. doi:10.1124/ mol.104.009001

139. Strotmann R, Schrock K, Boselt I, Staubert C, Russ A, Schoneberg T. Evolution of GPCR: change and continuity. Mol Cell Endocrinol (2011) 331:170-8. doi:10.1016/j.mce.2010.07.012

140. Kimple AJ, Bosch DE, Giguere PM, Siderovski DP. Regulators of G-protein signaling and their Galpha substrates: promises and challenges in their use as drug discovery targets. Pharmacol Rev (2011) 63:728-49. doi:10.1124/pr. 110.003038

141. O'Hayre M, Vazquez-Prado J, Kufareva I, Stawiski EW, Handel TM, Seshagiri $\mathrm{S}$, et al. The emerging mutational landscape of $\mathrm{G}$ proteins and G-protein-coupled receptors in cancer. Nat Rev Cancer (2013) 13:412-24. doi:10.1038/nrc3521

142. Plagge A, Kelsey G, Germain-Lee EL. Physiological functions of the imprinted Gnas locus and its protein variants Galpha(s) and XLalpha(s) in human and mouse. J Endocrinol (2008) 196:193-214. doi:10.1677/JOE07-0544

143. Kleinau G, Kalveram L, Kohrle J, Szkudlinski M, Schomburg L, Biebermann $\mathrm{H}$, et al. Minireview: insights into the structural and molecular consequences of the TSH-beta mutation C105Vfs114X. Mol Endocrinol (2016) 30:954-64. doi:10.1210/me.2016-1065

144. Schoenmakers N, Alatzoglou KS, Chatterjee VK, Dattani MT. Recent advances in central congenital hypothyroidism. J Endocrinol (2015) 227: R51-71. doi:10.1530/JOE-15-0341

145. Fox KM, Dias JA, Van Roey P. Three-dimensional structure of human follicle-stimulating hormone. Mol Endocrinol (2001) 15:378-89. doi:10.1210/ mend.15.3.0603

146. Wu H, Lustbader JW, Liu Y, Canfield RE, Hendrickson WA. Structure of human chorionic gonadotropin at 2.6 A resolution from MAD analysis of the selenomethionyl protein. Structure (1994) 2:545-58. doi:10.1016/ S0969-2126(00)00054-X

147. Lapthorn AJ, Harris DC, Littlejohn A, Lustbader JW, Canfield RE, Machin KJ, et al. Crystal structure of human chorionic gonadotropin. Nature (1994) 369:455-61. doi:10.1038/369455a0

148. Tegoni M, Spinelli S, Verhoeyen M, Davis P, Cambillau C. Crystal structure of a ternary complex between human chorionic gonadotropin (hCG) and two Fv fragments specific for the alpha and beta-subunits. J Mol Biol (1999) 289:1375-85. doi:10.1006/jmbi.1999.2845

149. Chen CR, Hubbard PA, Salazar LM, McLachlan SM, Murali R, Rapoport B. Crystal structure of a TSH receptor monoclonal antibody: insight into Graves' disease pathogenesis. Mol Endocrinol (2015) 29:99-107. doi:10.1210/ me.2014-1257

150. Graves PN, Vlase H, Bobovnikova Y, Davies TF. Multimeric complex formation by the thyrotropin receptor in solubilized thyroid membranes. Endocrinology (1996) 137:3915-20. doi:10.1210/en.137.9.3915

151. Graves PN, Vlase H, Davies TF. Folding of the recombinant human thyrotropin (TSH) receptor extracellular domain: identification of folded monomeric and tetrameric complexes that bind TSH receptor autoantibodies. Endocrinology (1995) 136:521-7. doi:10.1210/en.136.2.521

152. Manglik A, Kruse AC, Kobilka TS, Thian FS, Mathiesen JM, Sunahara RK, et al. Crystal structure of the micro-opioid receptor bound to a morphinan antagonist. Nature (2012) 485:321-6. doi:10.1038/nature10954

153. Wu H, Wacker D, Mileni M, Katritch V, Han GW, Vardy E, et al. Structure of the human kappa-opioid receptor in complex with JDTic. Nature (2012) 485:327-32. doi:10.1038/nature10939

154. Wu B, Chien EY, Mol CD, Fenalti G, Liu W, Katritch V, et al. Structures of the CXCR4 chemokine GPCR with small-molecule and cyclic peptide antagonists. Science (2010) 330:1066-71. doi:10.1126/science.1194396

155. Huang J, Chen S, Zhang JJ, Huang XY. Crystal structure of oligomeric beta1-adrenergic $\mathrm{G}$ protein-coupled receptors in ligand-free basal state. Nat Struct Mol Biol (2013) 20:419-25. doi:10.1038/nsmb.2504
156. Coke CJ, Scarlett KA, Chetram MA, Jones KJ, Sandifer BJ, Davis AS, et al. Simultaneous activation of induced heterodimerization between CXCR4 chemokine receptor and cannabinoid receptor 2 (CB2) reveals a mechanism for regulation of tumor progression. J Biol Chem (2016) 291:9991-10005. doi:10.1074/jbc.M115.712661

157. Gaitonde SA, Gonzalez-Maeso J. Contribution of heteromerization to G protein-coupled receptor function. Curr Opin Pharmacol (2016) 32:23-31. doi:10.1016/j.coph.2016.10.006

158. Liu H, Tian Y, Ji B, Lu H, Xin Q, Jiang Y, et al. Heterodimerization of the kappa opioid receptor and neurotensin receptor 1 contributes to a novel beta-arrestin-2-biased pathway. Biochim Biophys Acta (2016) 1863:2719-38. doi:10.1016/j.bbamcr.2016.07.009

159. Rozenfeld R, Devi LA. Receptor heteromerization and drug discovery. Trends Pharmacol Sci (2010) 31:124-30. doi:10.1016/j.tips.2009.11.008

160. Rozenfeld R, Devi LA. Exploring a role for heteromerization in GPCR signalling specificity. Biochem J (2011) 433:11-8. doi:10.1042/BJ20100458

161. Petryszak R, Keays M, Tang YA, Fonseca NA, Barrera E, Burdett T, et al. Expression atlas update - an integrated database of gene and protein expression in humans, animals and plants. Nucleic Acids Res (2016) 44:D746-52. doi:10.1093/nar/gkv1045

162. Kang Y, Zhou XE, Gao X, He Y, Liu W, Ishchenko A, et al. Crystal structure of rhodopsin bound to arrestin by femtosecond X-ray laser. Nature (2015) 523:561-7. doi:10.1038/nature14656

163. Zhou XE, Gao X, Barty A, Kang Y, He Y, Liu W, et al. X-ray laser diffraction for structure determination of the rhodopsin-arrestin complex. Sci Data (2016) 3:160021. doi:10.1038/sdata.2016.21

164. Szczepek M, Beyriere F, Hofmann KP, Elgeti M, Kazmin R, Rose A, et al. Crystal structure of a common GPCR-binding interface for G protein and arrestin. Nat Commun (2014) 5:4801. doi:10.1038/ncomms5801

165. Zhan X, Gimenez LE, Gurevich VV, Spiller BW. Crystal structure of arrestin-3 reveals the basis of the difference in receptor binding between two non-visual subtypes. J Mol Biol (2011) 406:467-78. doi:10.1016/j.jmb.2010.12.034

166. Kim YJ, Hofmann KP, Ernst OP, Scheerer P, Choe HW, Sommer ME. Crystal structure of pre-activated arrestin p44. Nature (2013) 497:142-6. doi:10.1038/ nature 12133

167. Shukla AK, Manglik A, Kruse AC, Xiao K, Reis RI, Tseng WC, et al. Structure of active beta-arrestin-1 bound to a G-protein-coupled receptor phosphopeptide. Nature (2013) 497:137-41. doi:10.1038/nature12120

168. Coleman DE, Berghuis AM, Lee E, Linder ME, Gilman AG, Sprang SR. Structures of active conformations of Gi alpha 1 and the mechanism of GTP hydrolysis. Science (1994) 265:1405-12. doi:10.1126/ science. 8073283

169. Wall MA, Coleman DE, Lee E, Iniguez-Lluhi JA, Posner BA, Gilman AG, et al. The structure of the $\mathrm{G}$ protein heterotrimer $\mathrm{Gi}$ alpha 1 beta 1 gamma 2. Cell (1995) 83:1047-58. doi:10.1016/0092-8674(95)90220-1

170. Sunahara RK, Tesmer JJ, Gilman AG, Sprang SR. Crystal structure of the adenylyl cyclase activator Gsalpha. Science (1997) 278:1943-7. doi:10.1126/ science.278.5345.1943

171. Nishimura A, Kitano K, Takasaki J, Taniguchi M, Mizuno N, Tago K, et al. Structural basis for the specific inhibition of heterotrimeric Gq protein by a small molecule. Proc Natl Acad Sci U S A (2010) 107:13666-71. doi:10.1073/ pnas. 1003553107

172. Waldo GL, Ricks TK, Hicks SN, Cheever ML, Kawano T, Tsuboi K, et al. Kinetic scaffolding mediated by a phospholipase C-beta and Gq signaling complex. Science (2010) 330:974-80. doi:10.1126/science.1193438

173. Tesmer VM, Kawano T, Shankaranarayanan A, Kozasa T, Tesmer JJ. Snapshot of activated G proteins at the membrane: the Galphaq-GRK2-Gbetagamma complex. Science (2005) 310:1686-90. doi:10.1126/science.1118890

174. Sower SA, Decatur WA, Hausken KN, Marquis TJ, Barton SL, Gargan J, et al. Emergence of an ancestral glycoprotein hormone in the pituitary of the sea lamprey, a basal vertebrate. Endocrinology (2015) 156:3026-37. doi:10.1210/ en.2014-1797

175. Nakabayashi K, Matsumi H, Bhalla A, Bae J, Mosselman S, Hsu SY, et al. Thyrostimulin, a heterodimer of two new human glycoprotein hormone subunits, activates the thyroid-stimulating hormone receptor. J Clin Invest (2002) 109:1445-52. doi:10.1172/JCI0214340

176. Okada SL, Ellsworth JL, Durnam DM, Haugen HS, Holloway JL, Kelley ML, et al. A glycoprotein hormone expressed in corticotrophs exhibits unique 
binding properties on thyroid-stimulating hormone receptor. Mol Endocrinol (2006) 20:414-25. doi:10.1210/me.2005-0270

177. Jaschke H, Neumann S, Moore S, Thomas CJ, Colson AO, Costanzi S, et al. A low molecular weight agonist signals by binding to the transmembrane domain of thyroid-stimulating hormone receptor (TSHR) and luteinizing hormone/chorionic gonadotropin receptor (LHCGR). J Biol Chem (2006) 281:9841-4. doi:10.1074/jbc.C600014200

178. Boutin A, Eliseeva E, Gershengorn MC, Neumann S. beta-Arrestin-1 mediates thyrotropin-enhanced osteoblast differentiation. FASEB J (2014) 28:3446-55. doi:10.1096/f.14-251124

179. Frenzel R, Voigt C, Paschke R. The human thyrotropin receptor is predominantly internalized by beta-arrestin 2. Endocrinology (2006) 147:3114-22. doi:10.1210/en.2005-0687

180. Neumann S, Geras-Raaka E, Marcus-Samuels B, Gershengorn MC. Persistent cAMP signaling by thyrotropin (TSH) receptors is not dependent on internalization. FASEB J (2010) 24:3992-9. doi:10.1096/fj.10-161745

181. Werthmann RC, Volpe S, Lohse MJ, Calebiro D. Persistent cAMP signaling by internalized TSH receptors occurs in thyroid but not in HEK293 cells. FASEB J (2012) 26:2043-8. doi:10.1096/fj.11-195248

182. Zoenen M, Urizar E, Swillens S, Vassart G, Costagliola S. Evidence for activityregulated hormone-binding cooperativity across glycoprotein hormone receptor homomers. Nat Commun (2012) 3:1007. doi:10.1038/ncomms1991

183. Urizar E, Montanelli L, Loy T, Bonomi M, Swillens S, Gales C, et al. Glycoprotein hormone receptors: link between receptor homodimerization and negative cooperativity. EMBO J (2005) 24:1954-64. doi:10.1038/sj. emboj.7600686

184. Latif R, Michalek K, Davies TF. Subunit interactions influence TSHR multimerization. Mol Endocrinol (2010) 24:2009-18. doi:10.1210/me.2010-0001

185. Audet M, Bouvier M. Restructuring G-protein-coupled receptor activation. Cell (2012) 151:14-23. doi:10.1016/j.cell.2012.09.003

186. Baltoumas FA, Theodoropoulou MC, Hamodrakas SJ. Molecular dynamics simulations and structure-based network analysis reveal structural and functional aspects of G-protein coupled receptor dimer interactions. J Comput Aided Mol Des (2016) 30:489-512. doi:10.1007/s10822-016-9919-y

187. Kaczur V, Puskas LG, Takacs M, Racz IA, Szendroi A, Toth S, et al. Evolution of the thyrotropin receptor: a $\mathrm{G}$ protein coupled receptor with an intrinsic capacity to dimerize. Mol Genet Metab (2003) 78:275-90. doi:10.1016/S10967192(03)00036-2

188. Latif R, Graves P, Davies TF. Oligomerization of the human thyrotropin receptor: fluorescent protein-tagged hTSHR reveals post-translational complexes. J Biol Chem (2001) 276:45217-24. doi:10.1074/jbc.M103727200

189. Kleinau G, Jaschke H, Neumann S, Lattig J, Paschke R, Krause G. Identification of a novel epitope in the thyroid-stimulating hormone receptor ectodomain acting as intramolecular signaling interface. J Biol Chem (2004) 279:51590-600. doi:10.1074/jbc.M404748200

190. Busnelli M, Kleinau G, Muttenthaler M, Stoev S, Manning M, Bibic L, et al. Design and characterization of superpotent bivalent ligands targeting oxytocin receptor dimers via a channel-like structure. J Med Chem (2016) 59:7152-66. doi:10.1021/acs.jmedchem.6b00564

191. Tate RL, Schwartz HI, Holmes JM, Kohn LD. Thyrotropin receptors in thyroid plasma membranes. Characteristics of thyrotropin binding and solubilization of thyrotropin receptor activity by tryptic digestion. J Biol Chem (1975) 250:6509-15.

192. Mueller S, Kleinau G, Jaeschke H, Paschke R, Krause G. Extended hormone binding site of the human thyroid stimulating hormone receptor: distinctive acidic residues in the hinge region are involved in bovine thyroid stimulating hormone binding and receptor activation. J Biol Chem (2008) 283:18048-55. doi:10.1074/jbc.M800449200

193. Mueller S, Kleinau G, Szkudlinski MW, Jaeschke H, Krause G, Paschke R. The superagonistic activity of bovine thyroid-stimulating hormone (TSH) and the human TR1401 TSH analog is determined by specific amino acids in the hinge region of the human TSH receptor. J Biol Chem (2009) 284:16317-24. doi:10.1074/jbc.M109.005710

194. Mueller S, Szkudlinski MW, Schaarschmidt J, Gunther R, Paschke R, Jaeschke H. Identification of novel TSH interaction sites by systematic binding analysis of the TSHR hinge region. Endocrinology (2011) 152:3268-78. doi:10.1210/en.2011-0153

195. Chen CR, McLachlan SM, Rapoport B. Evidence that the thyroid-stimulating hormone (TSH) receptor transmembrane domain influences kinetics of
TSH binding to the receptor ectodomain. J Biol Chem (2011) 286:6219-24. doi:10.1074/jbc.M110.211003

196. Chen CR, Salazar LM, McLachlan SM, Rapoport B. The thyrotropin receptor hinge region as a surrogate ligand: identification of loci contributing to the coupling of thyrotropin binding and receptor activation. Endocrinology (2012) 153:5058-67. doi:10.1210/en.2012-1376

197. Hamidi S, Chen CR, Mizutori-Sasai Y, McLachlan SM, Rapoport B. Relationship between thyrotropin receptor hinge region proteolytic posttranslational modification and receptor physiological function. Mol Endocrinol (2011) 25:184-94. doi:10.1210/me.2010-0401

198. Jaeschke H, Schaarschmidt J, Gunther R, Mueller S. The hinge region of the TSH receptor stabilizes ligand binding and determines different signaling profiles of human and bovine TSH. Endocrinology (2011) 152:3986-96. doi:10.1210/en.2011-1389

199. Mizutori Y, Chen CR, McLachlan SM, Rapoport B. The thyrotropin receptor hinge region is not simply a scaffold for the leucine-rich domain but contributes to ligand binding and signal transduction. Mol Endocrinol (2008) 22:1171-82. doi:10.1210/me.2007-0407

200. Mueller S, Kleinau G, Jaeschke H, Neumann S, Krause G, Paschke R. Significance of ectodomain cysteine boxes 2 and 3 for the activation mechanism of the thyroid-stimulating hormone receptor. J Biol Chem (2006) 281:31638-46. doi:10.1074/jbc.M604770200

201. Vlaeminck-Guillem V, Ho SC, Rodien P, Vassart G, Costagliola S. Activation of the cAMP pathway by the TSH receptor involves switching of the ectodomain from a tethered inverse agonist to an agonist. Mol Endocrinol (2002) 16:736-46. doi:10.1210/mend.16.4.0816

202. Schaarschmidt J, Huth S, Meier R, Paschke R, Jaeschke H. Influence of the hinge region and its adjacent domains on binding and signaling patterns of the thyrotropin and follitropin receptor. PLoS One (2014) 9:e111570. doi:10.1371/journal.pone.0111570

203. Chen CR, Chazenbalk GD, McLachlan SM, Rapoport B. Evidence that the $\mathrm{C}$ terminus of the A subunit suppresses thyrotropin receptor constitutive activity. Endocrinology (2003) 144:3821-7. doi:10.1210/en.2003-0430

204. Zhang M, Tong KP, Fremont V, Chen J, Narayan P, Puett D, et al. The extracellular domain suppresses constitutive activity of the transmembrane domain of the human TSH receptor: implications for hormone-receptor interaction and antagonist design. Endocrinology (2000) 141:3514-7. doi:10.1210/endo. 141.9.7790

205. Zhang ML, Sugawa H, Kosugi S, Mori T. Constitutive activation of the thyrotropin receptor by deletion of a portion of the extracellular domain. Biochem Biophys Res Commun (1995) 211:205-10. doi:10.1006/bbrc.1995.1797

206. Schoneberg T, Kleinau G, Bruser A. What are they waiting for? - tethered agonism in G protein-coupled receptors. Pharmacol Res (2016) 108:9-15. doi:10.1016/j.phrs.2016.03.027

207. Kleinau G, Jaeschke H, Mueller S, Raaka BM, Neumann S, Paschke R, et al. Evidence for cooperative signal triggering at the extracellular loops of the TSH receptor. FASEB J (2008) 22:2798-808. doi:10.1096/fi.07-104711

208. Ahuja S, Smith SO. Multiple switches in G protein-coupled receptor activation. Trends Pharmacol Sci (2009) 30:494-502. doi:10.1016/j.tips.2009.06.003

209. Kobilka B, Schertler GF. New G-protein-coupled receptor crystal structures: insights and limitations. Trends Pharmacol Sci (2008) 29:79-83. doi:10.1016/ j.tips.2007.11.009

210. Kobilka BK. Structural insights into adrenergic receptor function and pharmacology. Trends Pharmacol Sci (2011) 32:213-8. doi:10.1016/j.tips. 2011.02.005

211. Kobilka BK, Deupi X. Conformational complexity of G-protein-coupled receptors. Trends Pharmacol Sci (2007) 28:397-406. doi:10.1016/j. tips.2007.06.003

212. Karges B, Krause G, Homoki J, Debatin KM, de Roux N, Karges W. TSH receptor mutation V509A causes familial hyperthyroidism by release of interhelical constraints between transmembrane helices TMH3 and TMH5. J Endocrinol (2005) 186:377-85. doi:10.1677/joe.1.06208

213. Huang W, Manglik A, Venkatakrishnan AJ, Laeremans T, Feinberg EN, Sanborn AL, et al. Structural insights into mu-opioid receptor activation. Nature (2015) 524:315-21. doi:10.1038/nature14886

214. Sykiotis GP, Neumann S, Georgopoulos NA, Sgourou A, Papachatzopoulou A, Markou KB, et al. Functional significance of the thyrotropin receptor germline polymorphism D727E. Biochem Biophys Res Commun (2003) 301:1051-6. doi:10.1016/S0006-291X(03)00071-8 
215. Bokoch MP, Zou Y, Rasmussen SG, Liu CW, Nygaard R, Rosenbaum DM, et al. Ligand-specific regulation of the extracellular surface of a G-proteincoupled receptor. Nature (2010) 463:108-12. doi:10.1038/nature08650

216. Claus M, Jaeschke H, Kleinau G, Neumann S, Krause G, Paschke R. A hydrophobic cluster in the center of the third extracellular loop is important for thyrotropin receptor signaling. Endocrinology (2005) 146:5197-203. doi:10.1210/ en.2005-0713

217. Neumann S, Claus M, Paschke R. Interactions between the extracellular domain and the extracellular loops as well as the 6th transmembrane domain are necessary for TSH receptor activation. Eur J Endocrinol (2005) 152:625-34. doi:10.1530/eje.1.01891

218. Claeysen S, Govaerts C, Lefort A, Van Sande J, Costagliola S, Pardo L, et al. A conserved Asn in TM7 of the thyrotropin receptor is a common requirement for activation by both mutations and its natural agonist. FEBS Lett (2002) 517:195-200. doi:10.1016/S0014-5793(02)02620-0

219. Neumann S, Krause G, Chey S, Paschke R. A free carboxylate oxygen in the side chain of position 674 in transmembrane domain 7 is necessary for TSH receptor activation. Mol Endocrinol (2001) 15:1294-305. doi:10.1210/ mend.15.8.0672

220. Biebermann H, Schoneberg T, Schulz A, Krause G, Gruters A, Schultz G, et al. A conserved tyrosine residue (Y601) in transmembrane domain 5 of the human thyrotropin receptor serves as a molecular switch to determine G-protein coupling. FASEB J (1998) 12:1461-71.

221. Claus M, Neumann S, Kleinau G, Krause G, Paschke R. Structural determinants for G-protein activation and specificity in the third intracellular loop of the thyroid-stimulating hormone receptor. J Mol Med (2006) 84:943-54. doi:10.1007/s00109-006-0087-8

222. Parma J, Duprez L, Van Sande J, Cochaux P, Gervy C, Mockel J, et al. Somatic mutations in the thyrotropin receptor gene cause hyperfunctioning thyroid adenomas. Nature (1993) 365:649-51. doi:10.1038/365649a0

223. Angel TE, Chance MR, Palczewski K. Conserved waters mediate structural and functional activation of family A (rhodopsin-like) G protein-coupled receptors. Proc Natl Acad Sci U S A (2009) 106:8555-60. doi:10.1073/pnas. 0903545106

224. Katritch V, Fenalti G, Abola EE, Roth BL, Cherezov V, Stevens RC. Allosteric sodium in class A GPCR signaling. Trends Biochem Sci (2014) 39:233-44. doi:10.1016/j.tibs.2014.03.002

225. Mason JS, Bortolato A, Congreve M, Marshall FH. New insights from structural biology into the druggability of $\mathrm{G}$ protein-coupled receptors. Trends Pharmacol Sci (2012) 33:249-60. doi:10.1016/j.tips.2012.02.005

226. Salon JA, Lodowski DT, Palczewski K. The significance of G proteincoupled receptor crystallography for drug discovery. Pharmacol Rev (2011) 63:901-37. doi:10.1124/pr.110.003350

227. Yuan S, Palczewski K, Peng Q, Kolinski M, Vogel H, Filipek S. The mechanism of ligand-induced activation or inhibition of mu- and kappa-opioid receptors. Angew Chem Int Ed Engl (2015) 54:7560-3. doi:10.1002/anie.201501742

228. Blankenship E, Vahedi-Faridi A, Lodowski DT. The high-resolution structure of activated opsin reveals a conserved solvent network in the transmembrane region essential for activation. Structure (2015) 23:2358-64. doi:10.1016/ j.str.2015.09.015

229. Standfuss J, Edwards PC, D’Antona A, Fransen M, Xie G, Oprian DD, et al. The structural basis of agonist-induced activation in constitutively active rhodopsin. Nature (2011) 471:656-60. doi:10.1038/nature09795

230. Haas AK, Kleinau G, Hoyer I, Neumann S, Furkert J, Rutz C, et al. Mutations that silence constitutive signaling activity in the allosteric ligand-binding site of the thyrotropin receptor. Cell Mol Life Sci (2011) 68:159-67. doi:10.1007/ s00018-010-0451-2

231. Hoyer I, Haas AK, Kreuchwig A, Schulein R, Krause G. Molecular sampling of the allosteric binding pocket of the TSH receptor provides discriminative pharmacophores for antagonist and agonists. Biochem Soc Trans (2013) 41: 213-7. doi:10.1042/BST20120319

232. Chazenbalk GD, Nagayama Y, Russo D, Wadsworth HL, Rapoport B. Functional analysis of the cytoplasmic domains of the human thyrotropin receptor by site-directed mutagenesis. J Biol Chem (1990) 265:20970-5.

233. Kosugi S, Kohn LD, Akamizu T, Mori T. The middle portion in the second cytoplasmic loop of the thyrotropin receptor plays a crucial role in adenylate cyclase activation. Mol Endocrinol (1994) 8:498-509. doi:10.1210/ me.8.4.498
234. Kosugi S, Mori T. The amino-terminal half of the cytoplasmic tail of the thyrotropin receptor is essential for full activities of receptor function. Biochem Biophys Res Commun (1994) 200:401-7. doi:10.1006/bbrc.1994.1463

235. Kosugi S, Mori T. The first cytoplasmic loop of the thyrotropin receptor is important for phosphoinositide signaling but not for agonist-induced adenylate cyclase activation. FEBS Lett (1994) 341:162-6. doi:10.1016/00145793(94)80449-4

236. Camilot M, Teofoli F, Gandini A, Franceschi R, Rapa A, Corrias A, et al. Thyrotropin receptor gene mutations and TSH resistance: variable expressivity in the heterozygotes. Clin Endocrinol (Oxf) (2005) 63:146-51. doi:10.1111/ j.1365-2265.2005.02314.x

237. Cangul H, Morgan NV, Forman JR, Saglam H, Aycan Z, Yakut T, et al. Novel TSHR mutations in consanguineous families with congenital nongoitrous hypothyroidism. Clin Endocrinol (Oxf) (2010) 73:671-7. doi:10.1111/j.13652265.2010.03849.x

238. de Roux N, Misrahi M, Brauner R, Houang M, Carel JC, Granier M, et al. Four families with loss of function mutations of the thyrotropin receptor. J Clin Endocrinol Metab (1996) 81:4229-35. doi:10.1210/jcem.81.12. 8954020

239. Nishihara E, Nagayama Y, Amino N, Hishinuma A, Takano T, Yoshida H, et al. A novel thyrotropin receptor germline mutation (Asp617Tyr) causing hereditary hyperthyroidism. Endocr J (2007) 54:927-34. doi:10.1507/endocrj.K07-088

240. Venkatakrishnan AJ, Deupi X, Lebon G, Heydenreich FM, Flock T, Miljus T, et al. Diverse activation pathways in class A GPCRs converge near the G-proteincoupling region. Nature (2016) 536:484-7. doi:10.1038/nature19107

241. Oldham WM, Van Eps N, Preininger AM, Hubbell WL, Hamm HE Mechanism of the receptor-catalyzed activation of heterotrimeric $\mathrm{G}$ proteins. Nat Struct Mol Biol (2006) 13:772-7. doi:10.1038/nsmb1129

242. Smrcka AV. G protein betagamma subunits: central mediators of $G$ proteincoupled receptor signaling. Cell Mol Life Sci (2008) 65:2191-214. doi:10.1007/ s00018-008-8006-5

243. Neumann S, Krause G, Claus M, Paschke R. Structural determinants for g protein activation and selectivity in the second intracellular loop of the thyrotropin receptor. Endocrinology (2005) 146:477-85. doi:10.1210/en. 2004-1045

244. Chang WC, Liao CY, Chen WC, Fan YC, Chiu SJ, Kuo HC, et al. R450H TSH receptor mutation in congenital hypothyroidism in Taiwanese children. Clin Chim Acta (2012) 413:1004-7. doi:10.1016/j.cca.2012.02.027

245. Mizuno H, Kanda K, Sugiyama Y, Imamine H, Ito T, Kato I, et al. Longitudinal evaluation of patients with a homozygous $\mathrm{R} 450 \mathrm{H}$ mutation of the TSH receptor gene. Horm Res (2009) 71:318-23. doi:10.1159/000223415

246. Nagashima T, Murakami M, Onigata K, Morimura T, Nagashima K, Mori M, et al. Novel inactivating missense mutations in the thyrotropin receptor gene in Japanese children with resistance to thyrotropin. Thyroid (2001) 11:551-9. doi:10.1089/105072501750302859

247. Narumi S, Nagasaki K, Ishii T, Muroya K, Asakura Y, Adachi M, et al. Nonclassic TSH resistance: TSHR mutation carriers with discrepantly high thyroidal iodine uptake. J Clin Endocrinol Metab (2011) 96:E1340-5. doi:10.1210/ jc. 2011-0070

248. Sounier R, Mas C, Steyaert J, Laeremans T, Manglik A, Huang W, et al. Propagation of conformational changes during mu-opioid receptor activation. Nature (2015) 524:375-8. doi:10.1038/nature14680

249. Van Sande J, Parma J, Tonacchera M, Swillens S, Dumont J, Vassart G. Somatic and germline mutations of the TSH receptor gene in thyroid diseases. J Clin Endocrinol Metab (1995) 80:2577-85. doi:10.1210/jc.80.9.2577

250. Harikumar KG, Morfis MM, Sexton PM, Miller LJ. Pattern of intra-family hetero-oligomerization involving the G-protein-coupled secretin receptor. J Mol Neurosci (2008) 36:279-85. doi:10.1007/s12031-008-9060-z

251. Li X, Staszewski L, Xu H, Durick K, Zoller M, Adler E. Human receptors for sweet and umami taste. Proc Natl Acad Sci U S A (2002) 99:4692-6. doi:10.1073/pnas.072090199

252. Ng HK, Chow BK. Oligomerization of family B GPCRs: exploration in inter-family oligomer formation. Front Endocrinol (2015) 6:10. doi:10.3389/ fendo.2015.00010

253. Ng SY, Lee LT, Chow BK. Receptor oligomerization: from early evidence to current understanding in class B GPCRs. Front Endocrinol (2012) 3:175. doi: $10.3389 /$ fendo. 2012.00175 
254. Ciruela F, Vilardaga JP, Fernandez-Duenas V. Lighting up multiprotein complexes: lessons from GPCR oligomerization. Trends Biotechnol (2010) 28:407-15. doi:10.1016/j.tibtech.2010.05.002

255. Smith NJ, Milligan G. Allostery at G protein-coupled receptor homo- and heteromers: uncharted pharmacological landscapes. Pharmacol Rev (2010) 62:701-25. doi:10.1124/pr.110.002667

256. White JF, Grodnitzky J, Louis JM, Trinh LB, Shiloach J, Gutierrez J, et al. Dimerization of the class A G protein-coupled neurotensin receptor NTS1 alters G protein interaction. Proc Natl Acad Sci U S A (2007) 104:12199-204. doi:10.1073/pnas.0705312104

257. Kleinau G, Muller A, Biebermann H. Oligomerization of GPCRs involved in endocrine regulation. J Mol Endocrinol (2016) 57:R59-80. doi:10.1530/ JME-16-0049

258. Ploier B, Caro LN, Morizumi T, Pandey K, Pearring JN, Goren MA, et al. Dimerization deficiency of enigmatic retinitis pigmentosa-linked rhodopsin mutants. Nat Commun (2016) 7:12832. doi:10.1038/ncomms12832

259. Rivero-Muller A, Chou YY, Ji I, Lajic S, Hanyaloglu AC, Jonas K, et al. Rescue of defective $G$ protein-coupled receptor function in vivo by intermolecular cooperation. Proc Natl Acad Sci U S A (2010) 107:2319-24. doi:10.1073/pnas. 0906695106

260. Tadagaki K, Jockers R, Kamal M. History and biological significance of GPCR heteromerization in the neuroendocrine system. Neuroendocrinology (2012) 95:223-31. doi:10.1159/000330000

261. Tadagaki K, Tudor D, Gbahou F, Tschische P, Waldhoer M, Bomsel M, et al. Human cytomegalovirus-encoded UL33 and UL78 heteromerize with host CCR5 and CXCR4 impairing their HIV coreceptor activity. Blood (2012) 119:4908-18. doi:10.1182/blood-2011-08-372516

262. Tschische P, Tadagaki K, Kamal M, Jockers R, Waldhoer M. Heteromerization of human cytomegalovirus encoded chemokine receptors. Biochem Pharmacol (2011) 82:610-9. doi:10.1016/j.bcp.2011.06.009

263. Levoye A, Dam J, Ayoub MA, Guillaume JL, Couturier C, Delagrange P, et al. The orphan GPR50 receptor specifically inhibits MT1 melatonin receptor function through heterodimerization. EMBO J (2006) 25:3012-23. doi:10.1038/sj.emboj.7601193

264. Lohse MJ. Dimerization in GPCR mobility and signaling. Curr Opin Pharmacol (2010) 10:53-8. doi:10.1016/j.coph.2009.10.007

265. Bouvier M. Oligomerization of G-protein-coupled transmitter receptors. Nat Rev Neurosci (2001) 2:274-86. doi:10.1038/35067575

266. George SR, O'Dowd BF, Lee SP. G-protein-coupled receptor oligomerization and its potential for drug discovery. Nat Rev Drug Discov (2002) 1:808-20. doi:10.1038/nrd913

267. Uberti MA, Hague C, Oller H, Minneman KP, Hall RA. Heterodimerization with beta2-adrenergic receptors promotes surface expression and functional activity of alpha1D-adrenergic receptors. J Pharmacol Exp Ther (2005) 313:16-23. doi:10.1124/jpet.104.079541

268. Persani L, Calebiro D, Bonomi M. Technology Insight: modern methods to monitor protein-protein interactions reveal functional TSH receptor oligomerization. Nat Clin Pract Endocrinol Metab (2007) 3:180-90. doi:10.1038/ ncpendmet 0401

269. Allen MD, Neumann S, Gershengorn MC. Occupancy of both sites on the thyrotropin (TSH) receptor dimer is necessary for phosphoinositide signaling. FASEB J (2011) 25:3687-94. doi:10.1096/fj.11-188961

270. Latif R, Graves P, Davies TF. Ligand-dependent inhibition of oligomerization at the human thyrotropin receptor. J Biol Chem (2002) 277:45059-67. doi:10.1074/jbc.M206693200

271. Davies T, Marians R, Latif R. The TSH receptor reveals itself. J Clin Invest (2002) 110:161-4. doi:10.1172/JCI0216234

272. Tenenbaum-Rakover Y, Grasberger H, Mamanasiri S, Ringkananont U, Montanelli L, Barkoff MS, et al. Loss-of-function mutations in the thyrotropin receptor gene as a major determinant of hyperthyrotropinemia in a consanguineous community. J Clin Endocrinol Metab (2009) 94:1706-12. doi:10.1210/jc.2008-1938

273. Calebiro D, de Filippis T, Lucchi S, Covino C, Panigone S, Beck-Peccoz P, et al. Intracellular entrapment of wild-type TSH receptor by oligomerization with mutants linked to dominant TSH resistance. Hum Mol Genet (2005) 14:2991-3002. doi:10.1093/hmg/ddi329

274. Biebermann H, Winkler F, Handke D, Teichmann A, Gerling B, Cameron F, et al. New pathogenic thyrotropin receptor mutations decipher differentiated activity switching at a conserved helix 6 motif of family A GPCR. J Clin Endocrinol Metab (2012) 97:E228-32. doi:10.1210/jc.2011-2106

275. Guo W, Shi L, Filizola M, Weinstein H, Javitch JA. Crosstalk in G proteincoupled receptors: changes at the transmembrane homodimer interface determine activation. Proc Natl Acad Sci U S A (2005) 102:17495-500. doi:10.1073/pnas.0508950102

276. Bakker RA, Dees G, Carrillo JJ, Booth RG, Lopez-Gimenez JF, Milligan G, et al. Domain swapping in the human histamine $\mathrm{H} 1$ receptor. J Pharmacol Exp Ther (2004) 311:131-8. doi:10.1124/jpet.104.067041

277. Mancia F, Assur Z, Herman AG, Siegel R, Hendrickson WA. Ligand sensitivity in dimeric associations of the serotonin 5HT2c receptor. EMBO Rep (2008) 9:363-9. doi:10.1038/embor.2008.27

278. Gorinski N, Kowalsman N, Renner U, Wirth A, Reinartz MT, Seifert R, et al. Computational and experimental analysis of the transmembrane domain 4/5 dimerization interface of the serotonin 5-HT(1A) receptor. Mol Pharmacol (2012) 82:448-63. doi:10.1124/mol.112.079137

279. George SR, Lee SP, Varghese G, Zeman PR, Seeman P, Ng GY, et al. A transmembrane domain-derived peptide inhibits D1 dopamine receptor function without affecting receptor oligomerization. J Biol Chem (1998) 273:30244-8. doi:10.1074/jbc.273.46.30244

280. Hu J, Hu K, Liu T, Stern MK, Mistry R, Challiss RA, et al. Novel structural and functional insights into M3 muscarinic receptor dimer/oligomer formation. J Biol Chem (2013) 288:34777-90. doi:10.1074/jbc.M113.503714

281. Yanagawa M, Yamashita T, Shichida Y. Comparative fluorescence resonance energy transfer analysis of metabotropic glutamate receptors: implications about the dimeric arrangement and rearrangement upon ligand bindings. J Biol Chem (2011) 286:22971-81. doi:10.1074/jbc.M110.206870

282. Latif R, Michalek K, Morshed SA, Davies TF. A tyrosine residue on the TSH receptor stabilizes multimer formation. PLoS One (2010) 5:e9449. doi:10.1371/ journal.pone.0009449

283. Latif R, Ali MR, Mezei M, Davies TF. Transmembrane domains of attraction on the TSH receptor. Endocrinology (2015) 156:488-98. doi:10.1210/en.2014-1509

284. Chazenbalk GD, Kakinuma A, Jaume JC, McLachlan SM, Rapoport B. Evidence for negative cooperativity among human thyrotropin receptors overexpressed in mammalian cells. Endocrinology (1996) 137:4586-91. doi:10.1210/endo.137.11.8895321

285. Jiang X, Fischer D, Chen X, McKenna SD, Liu H, Sriraman V, et al. Evidence for follicle-stimulating hormone receptor as a functional trimer. J Biol Chem (2014) 289:14273-82. doi:10.1074/jbc.M114.549592

286. Boutin A, Allen MD, Geras-Raaka E, Huang W, Neumann S, Gershengorn MC. Thyrotropin receptor stimulates internalization-independent persistent phosphoinositide signaling. Mol Pharmacol (2011) 80:240-6. doi:10.1124/mol. 111.072157

287. Calebiro D, Nikolaev VO, Gagliani MC, de Filippis T, Dees C, Tacchetti C, et al. Persistent cAMP-signals triggered by internalized G-protein-coupled receptors. PLoS Biol (2009) 7:e1000172. doi:10.1371/journal.pbio.1000172

288. Calebiro D, Nikolaev VO, Lohse MJ. Imaging of persistent cAMP signaling by internalized G protein-coupled receptors. J Mol Endocrinol (2010) 45:1-8. doi:10.1677/JME-10-0014

289. Calebiro D, Nikolaev VO, Persani L, Lohse MJ. Signaling by internalized G-protein-coupled receptors. Trends Pharmacol Sci (2010) 31:221-8. doi:10.1016/j.tips.2010.02.002

290. Calebiro D, Rieken F, Wagner J, Sungkaworn T, Zabel U, Borzi A, et al. Singlemolecule analysis of fluorescently labeled G-protein-coupled receptors reveals complexes with distinct dynamics and organization. Proc Natl Acad Sci U S A (2012) 110(2):743-8. doi:10.1073/pnas.1205798110

291. Cianfarani F, Baldini E, Cavalli A, Marchioni E, Lembo L, Teson M, et al. TSH receptor and thyroid-specific gene expression in human skin. J Invest Dermatol (2010) 130:93-101. doi:10.1038/jid.2009.180

292. Davies TF, Teng CS, McLachlan SM, Smith BR, Hall R. Thyrotropin receptors in adipose tissue, retro-orbital tissue and lymphocytes. Mol Cell Endocrinol (1978) 9:303-10. doi:10.1016/0303-7207(78)90072-2

293. de Lloyd A, Bursell J, Gregory JW, Rees DA, Ludgate M. TSH receptor activation and body composition. J Endocrinol (2010) 204:13-20. doi:10.1677/ JOE-09-0262

294. Liu Z, Ji Z, Wang G, Chao T, Hou L, Wang J. Genome-wide analysis reveals signatures of selection for important traits in domestic sheep from different ecoregions. BMC Genomics (2016) 17:863. doi:10.1186/s12864-016-3212-2 
295. Martinez Barrio A, Lamichhaney S, Fan G, Rafati N, Pettersson M, Zhang H, et al. The genetic basis for ecological adaptation of the Atlantic herring revealed by genome sequencing. Elife (2016) 5:e12081. doi:10.7554/ eLife. 12081

296. Ono H, Hoshino Y, Yasuo S, Watanabe M, Nakane Y, Murai A, et al. Involvement of thyrotropin in photoperiodic signal transduction in mice. Proc Natl Acad Sci U S A (2008) 105:18238-42. doi:10.1073/pnas.0808952105

Conflict of Interest Statement: The authors declare that the research was conducted in the absence of any commercial or financial relationships that could be construed as a potential conflict of interest.
The reviewer, $\mathrm{MM}$, and handling editor declared their shared affiliation, and the handling editor states that the process nevertheless met the standards of a fair and objective review.

Copyright $\odot 2017$ Kleinau, Worth, Kreuchwig, Biebermann, Marcinkowski, Scheerer and Krause. This is an open-access article distributed under the terms of the Creative Commons Attribution License (CC BY). The use, distribution or reproduction in other forums is permitted, provided the original author(s) or licensor are credited and that the original publication in this journal is cited, in accordance with accepted academic practice. No use, distribution or reproduction is permitted which does not comply with these terms. 